\title{
Covalent Organic Framework Photocatalysts: Structures and Applications
}

Received 00th January 20xx, Accepted 00th January 20xx

DOI: $10.1039 / \times 0 \times x 00000 x$

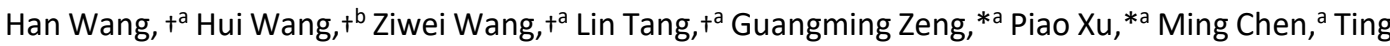 \\ Xiong, ${ }^{\text {a }}$ Chengyun Zhou, ${ }^{a}$ Xiyi Li, ${ }^{\text {b }}$ Yuan Zhu, ${ }^{\text {a }}$ Zixuan Wang ${ }^{\text {a }}$ and Junwang Tang $*$ b
}

\section{Introduction}

With the rapid industrialization and urbanization, there has never been a greater concern towards the sustainable supply of fossil fuels (e.g. oil, coal and gas) and the severe environmental issues caused by utilization of these fossil fuels. ${ }^{1-3}$ Thus, it is urgent to secure an alternative, sustainable, clean energy source by an operative and scalable technology to address the environment and energy issues for the society. Solar driven chemical processes including water splitting, $\mathrm{CO}_{2}$ conversion, photocatalytic degradation, etc., have attracted substantial interest because of solar energy as an abundant and inexhaustible source. The method to utilize solar energy is denoted as photocatalysis in which when the energy of photons is greater than the semiconductor band gap, the electrons from the valence band (VB) can be excited to the conduction band ( $C B$ ), creating the electron/hole pairs in the photocatalysts. Then the separated electrons and holes mitigate to the surface to participate in the chemical reactions.

In 1970's, Fujishima and Honda realized the water splitting under ultraviolet (UV) radiation by using titanium dioxide $\left(\mathrm{TiO}_{2}\right)$ electrode for the first time. ${ }^{4}$ And Carey et al. carried out the

\footnotetext{
a. College of Environmental Science and Engineering, Hunan University and Key Laboratory of Environmental Biology and Pollution Control (Hunan University), Ministry of Education, Changsha 410082, P. R. China. E-mail: zgming@hnu.edu.cn; piaoxu@hnu.edu.cn.

b. Department of Chemical Engineering, University College London, Torrington Place, London, WC1E7JE, UK. E-mail: junwang.tang@ucl.ac.uk.

+ These authors contribute equally to this article.

Electronic Supplementary Information (ESI) available: [details of any supplementary information available should be included here]. See DOI: 10.1039/x0xx00000x
}

photocatalytic degradation of organic pollutants with $\mathrm{TiO}_{2}$ in aqueous suspensions four years later. ${ }^{5}$ These have sparked intense interest among researchers for artificial photosynthesis. Traditional semiconductor photocatalysts such as $\mathrm{TiO}_{2},{ }^{6-8}$ cadmium sulphide $(\mathrm{CdS}),{ }^{9-11}$ graphitic carbon nitride $\left(\mathrm{g}-\mathrm{C}_{3} \mathrm{~N}_{4}\right)^{12-14}$ and metal-organic frameworks (MOFs) $)^{15}, 16$ have occupied a leading position over the past decades. While $\mathrm{TiO}_{2}$ is the most important and well-known semiconductor photocatalyst by far, its wide band gap of $3.2 \mathrm{eV}$ that only allows for ultraviolet light absorption limits its utilization of solar spectrum, thus leading to the low photocatalytic efficiency. ${ }^{17} \mathrm{CdS}$ with suitable band gap to absorb visible light stimulated the attention of the photocatalytic studies, whereas the heavy metal toxicity and photocorrision effect block its practical applications. ${ }^{9}$ Also, organic semiconductor $\mathrm{g}-\mathrm{C}_{3} \mathrm{~N}_{4}$ has been recently widely used as a photocatalyst due to its appealing band gap as well as "earthabundant" nature. ${ }^{18}$ In parallel, MOFs constructed from organic linkers and transition-metal nodes are attractive due to their flexible pre-design synthesis and post-synthetic modification, while deficiencies still exist, such as limited physical and chemical stability, and photocorrosion. ${ }^{16}$ Therefore, developing well-defined materials with a visible light response, structural tunability, photochemical stability, and bio-compatibility are important for photocatalytic applications.

Covalent organic frameworks (COFs), as a newly developed organic polymer, have caused ripples of excitement among researchers striving to exploit their promising photocatalytic potentials. ${ }^{19-23}$ COFs with low density are crystalline porous materials composed of organic molecules linked by covalent bond through reticular chemistry, ${ }^{24,25}$ which have been widely used in areas such as heterogeneous catalysts, ${ }^{26-28}$ gas storage and separation, ${ }^{29}$ energy 
storage ${ }^{30,31}$ and optoelectronic devices (Fig. 1). ${ }^{32,33}$ Similar to MOFs, COFs synthesized from molecular building blocks endow them with chemical tunability to realize the design of targeted porous structures and special properties related to photocatalytic reactions such as light-harvesting capability, electron-hole separation and transfer. ${ }^{34}$ For example, donor-acceptor COF $D_{\mathrm{ZnPc}}-A_{\mathrm{NDI}}-\mathrm{COF}$ was designed and synthesized by condensation of electron donor zinc phthalocyanine with electron acceptor naphthalene diimide, which enabled an efficient electron transfer between the zinc phthalocyanine moiety and the naphthalene diimide unit. ${ }^{35}$ As a result, the $\mathrm{D}_{\mathrm{ZnP}}-\mathrm{A}_{\mathrm{NDI}}-\mathrm{COF}$ could absorb not only visible light but also near-infrared light. Another study suggested that photoconductive porous thieno[2,3-b]thiophene-based donor framework TT-COF was capable of encapsulating electron acceptor $[6,6]-$ phenyl- $\mathrm{C}_{61^{-}}$ butyricacid methyl ester (PCBM) in the pore, featuring light-induced charge-separation. ${ }^{36}$ On the other hand, 2D layered COFs with vertically $\pi$-stacked columns allow for the electronic interactions between COF layers, which provide a way for excitons and charge carrier transfer. ${ }^{37}$ Besides, COFs with covalent bonds own high thermal/chemical stability, and photoactive building blocks can be fixed in the rigid architecture, thus enhancing the lifetimes of the excited states by protecting them from collision and deactivation. ${ }^{38}$ These fascinating inherent features endow COFs with great potential in photocatalytic energy conversion and environmental remediation, which are deem to match or even exceed MOFs and conventional photocatalytic semiconductors. Lotsch and co-workers reported the first discovery of COF in photocatalysis. ${ }^{39} \mathrm{~A}$ high visible-light-induced hydrogen production efficiency has been achieved based on hydrazine-based TFPT-COF (evolution rate: $1970 \mu \mathrm{mol} \mathrm{h} \mathrm{h}^{-1} \mathrm{~g}^{-1}$, triethanolamine (TEOA) as a sacrificial donor), which was competitive with other representative photocatalysts including Ptmodified amorphous melon $\left(720 \mu \mathrm{mol} \mathrm{h}{ }^{-1} \mathrm{~g}^{-1}\right), \mathrm{g}-\mathrm{C}_{3} \mathrm{~N}_{4}$ synthesized at $600{ }^{\circ} \mathrm{C}\left(840 \mu \mathrm{mol} \mathrm{h} \mathrm{h}^{-1} \mathrm{~g}^{-1}\right),{ }^{40}$ and crystalline poly(triazine imide) (864 $\left.\mu \mathrm{mol} \mathrm{h} \mathrm{h}^{-1} \mathrm{~g}^{-1}\right) .^{41}$ This success has initiated the exploration of COFbased photocatalysts in the whole community.

There has been no comprehensive review for a full understanding of COF photocatalysis, although one review was published emphasizing on photocatalytic $\mathrm{H}_{2}$ evolution by COFs. ${ }^{20}$ In this review, we began by summarizing different connections of COF building blocks including boron-containing connections, nitrogencontaining connections and double-stage connections combining imine linkages and boronate ester linkages. Subsequently, we compared the performance of COFs over different morphologies, including 0-dimensional (OD), 1-dimensional (1D), 2-dimensional (2D), and 3-dimensional (3D) structures. Strategies related to the enhanced photocatalytic performance of COF materials were then presented. Afterwards, the solar-driven application of COFs was discussed, including water splitting, $\mathrm{CO}_{2}$ conversion as well as photocatalytic degradation of pollutants in wastewater. Finally, a perspective on the challenges and opportunities in this area, including synthesis, functions and application, was discussed. Complementary to this review, audience are also suggested to read another review about the design of COF if they are interested in the materials design. ${ }^{34,42-47}$

\section{Linking chemistry of COFs}

COFs are a kind of crystalline porous materials with pure organic groups connected by robust covalent bonds. Diverse covalent bonds formed from various synthetic organic reactions between theoretically unlimited building blocks endow COFs with designable crystalline structures and targeted functions. In this section, different linkages of COF building blocks were summarized, including boroncontaining linkage, triazine linkage, imine linkage, $\beta$-ketoenamines linkage, hydrazones and azines linkages, and other linkages (Fig. 2).

\subsection{Boron-containing linkage}

Since the pioneering research of Yaghi and co-workers that constructed the first two COFs, namely COF-1 and COF-5, diverse syntheses of COFs linked by boron-containing linkages via the formation of boronate ester, boroxine or borazine have generated considerable interest. ${ }^{24}$ The most synthesized boron-based COFs could be clarified into two categories: single building block selfcondensation and two or more building units co-condensation.

As a representative example, COF-1 was designed and fabricated through the self-condensation of 1, 4-benzenediboronic acid (BDBA), which was based on the molecular dehydration to form six-membered boroxine connections. ${ }^{24}$ The as-prepared COF-1 possessed a layered graphitic structure with the hexagonal pores diameter of $15 \AA$ and a Brunauer-Emmett-Teller (BET) surface area of $711 \mathrm{~m}^{2} \mathrm{~g}^{-1}$. In this method, control of the headspace in the sealed reaction tube modulated the amount of water, resulting in the reversibility of the condensation reaction to ultimately crystallize the COF. Similarly, the same group further successfully constructed the first 3D COFs (COF-102 and COF-103) with the self-condensation of the tetrahedral molecular building block tetra(4dihydroxyborylphenyl)methane (TBPM) or its silane analog (TBPS). ${ }^{48}$ The crystalline COF-102 and COF-103 exhibited a higher BET surface area of $3472 \mathrm{~m}^{2} \mathrm{~g}^{-1}$ and $4210 \mathrm{~m}^{2} \mathrm{~g}^{-1}$, respectively. Since then, this selfcondensation strategy has been widely used to fabricate boroncontaining COFs based on various monomers, such as biphenyldiboronic acid, ${ }^{49}$ pyrene-2, 7-diboronic acid (PDA), ${ }^{50}$ and 4 , 4'-phenylazobenzoyl diboronic acid (ABBA), ${ }^{51}$.

Besides self-condensation, the co-condensation of two or more building blocks such as boronic acids with catechols has also been reported. The dehydration condensation of $2,3,6,7,10$, 11hexahydroxytriphenylene (HHTP) and BDBA resulted in the formation of layered COF-5 with five-membered $\mathrm{BO}_{2} \mathrm{C}_{3}$ rings, which exhibited an eclipsed boron nitride arrangement. ${ }^{24}$ It is worth mentioning that COF- 5 has been widely regarded as a representative to examine various newly synthesis strategy..$^{52-54}$ Likewise, the first crystalline boronate-linked 3D COFs (COF-105 and COF-108) were obtained by replacing BDBA with tetrahedral molecules TBPM and TBPS, respectively. ${ }^{48}$ COFs with different properties and functions could be designed and synthesized by a diverse combination of building units. For instance, a novel photoactive donor-acceptor TPPor COF was prepared based on triphenylene and porphyrin units..$^{55}$ The resulting TP-Por COF film with enhanced charge separation showed a broad optical absorption covering the entire visible range up to $680 \mathrm{~nm}$. In a conventional condensation, donor-acceptor $D_{\text {TP- }}$ $A_{\mathrm{NDI}}-\mathrm{COF}$ with the large pore size of $5.3 \mathrm{~nm}$ was obtained from $\mathrm{N}, \mathrm{N}^{\prime}$ di-(4-boronophenyl)naphthalene-1,4,5,8-tetracarboxylic acid 
diimide (NDIDA) and HTTP. ${ }^{56}$ The charge-separation state lifetime of $2.5 \mu$ s was determined by time-resolved electron spin resonance spectroscopy, which demonstrated the existence of long-lived radical originating from an efficient charge transfer from the triphenylene donor phase to the naphthalene diimide acceptor phase. Notably, polyfunctional catechols are easy to oxidation and hard to dissolve in most organic solvents, leading to difficulty fabrication of functional building blocks and related COFs. Thus, a new Lewis acid-catalyzed strategy protecting catechols from oxidation was put forward. ${ }^{57}$ Boronate ester-linked Pc-PBBA COF with a pore size of $2.3 \mathrm{~nm}$ was constructed from 1,4phenylenebis(boronic acid) (PBBA) and phthalocyanine tetra(acetonide) $(\mathrm{PC})$ in the presence of Lewis-acid catalyst $\mathrm{BF}_{3} \cdot \mathrm{OEt}_{2}$. The as-prepared eclipsed COF with broad absorbance showed great potential for efficient charge transport through the stacked phthalocyanines. In contrast with the conventional condensation of two component, a multiple-component (MC) strategy was also studied. ${ }^{58}$ For example, three component [1+2] co-condensation by using the shortest unit BDBA and a longer molecule PDA at a molar ratio of 1:2 or 2:1 as the linkers to condense with HHTP as the knots. Two MC-COFs (termed MC-COF-TP- $\mathrm{E}_{1}{ }^{1} \mathrm{E}_{7}{ }^{2}$ and MC-COF-TP- $\mathrm{E}_{1}{ }^{2} \mathrm{E}_{7}{ }^{1}$ ) with slipped AA stacking were generated to possess the BET surface area of 1892 and $1534 \mathrm{~m}^{2} / \mathrm{g}$ and pore sizes of 3.2 and $2.9 \mathrm{~nm}$, respectively. Also, the functionality of COF materials could be tailored through this co-condensation strategy. A highly emissive $2 \mathrm{D}$ COF TPE-Ph COF was designed by introducing an aggregationinduced emission active tetraphenylethene (TPE) unit with the condensation of 1, 2, 4, 5-tetrahydroxybenzene (THB) and TPE-cored boronic acids (TPEBA). ${ }^{59}$ Considering that the boronate linkages in TPE-Ph COF formed Lewis acid-base pair when interacted with ammonia, TPE-Ph COF could be used as a fluorescence sensor for ammonia.

Generally, COFs with boron-containing linkages possess low density and high surface area, leading to various applications. ${ }^{60,61}$ However, boroxines and boronate ester are easy to hydrolysis and oxidation, and thereby limiting their application as catalysts or with long-term usage. Still, it is undeniable that boron-containing COFs are of particular importance for mechanistic study. ${ }^{52,62,63}$

\subsection{Triazine-based linkage}

In 2008, Thomas and co-workers reported the first example of triazine-based COFs (donated as CTFs), which was achieved by cyclotrimerization of aromatic nitriles at $400{ }^{\circ} \mathrm{C}$ with the catalysis of $\mathrm{ZnCl}_{2} \cdot{ }^{64}$ However, harsh synthesis conditions, such as high reaction temperature and acid solution purification, lead to the destruction of long-range order. Only a few crystalline CTFs have been prepared by this method constructed from 1, 3, 5-tricyanobenzene, 1, 4dicyanobenzene and 2, 6-dicyanonaphthalene monomers, namely CTF-0, CTF-1 and CTF-2, respectively. ${ }^{65,66}$ Moreover, limited building blocks are able to withstand the high reaction temperature, thus lowering the diversity of CTFs. Thus, other strategies based on milder conditions have been developed. ${ }^{67-69}$ A low-temperature polycondensation approach was utilized to synthesize CTFs based on a broader range of building blocks via mild conditions. ${ }^{70}$ For example, CTF-HUST-1 prepared from 1, 4-benzene-dialdehyde reacted at ambient pressure with a temperature lower than or equal to $120^{\circ} \mathrm{C}$, which also enabled the large scale synthesis. Soon afterward, a new concept was put forward to fabricate highly crystalline CTFs by in-suit oxidizing alcohol to form aldehyde with controlled reaction rates. The principle behind this reaction was that decreasing nucleation rates and lowering the concentration of nuclei could lead to relatively high crystallization. ${ }^{71}$ The as-prepared CTFs possessed muchimproved crystallinity and higher photocatalytic performance compared to low crystalline or amorphous CTFs. And a controlling feeding rate method was also used to achieve highly crystalline CTFs. ${ }^{72}$

Despite the crystalline problems, high BET surface area, remarkable thermal and chemical stabilities, and controllable $\mathrm{C} / \mathrm{N} / \mathrm{H}$ composition endow CTFs with potential for catalysis. 2D CTFs with triazine subunits can be regarded as analogs of $\mathrm{g}-\mathrm{C}_{3} \mathrm{~N}_{4}$, which has been studied extensively as metal-free photocatalyst. ${ }^{73,74}$ On the one hand, the incorporated nitrogen in backbone benefits for metal nanoparticle loading, which provides a platform for the introduction of the active sites for the catalytic reaction. On the other hand, the tunable structures with unlimited organic subunits allow for the controllable band alignment and optimal light absorption. ${ }^{75}$ Studies demonstrated that the photocatalytic hydrogen production of CTF-1 can be varied with different reaction conditions. For example, a wellordered CTF-1 was synthesized via a mild microwave-assisted condensation. ${ }^{76}$ Apparent quantum efficiency (AQE) of $3.8 \%$ and $6 \%$ at $420 \mathrm{~nm}$ for oxygen and hydrogen evolution under visible light irradiation was determined, respectively. In particular, the oxygen evolution rate and hydrogen evolution rate of CTF-1-100W were 140 $\mu \mathrm{mol} \mathrm{g} \mathrm{g}^{-1} \mathrm{~h}^{-1}$ and $5500 \mu \mathrm{mol} \mathrm{g} \mathrm{g}^{-1} \mathrm{~h}^{-1}$, respectively, both of which are higher than those of $\mathrm{g}-\mathrm{C}_{3} \mathrm{~N}_{4}{ }^{73,77}$ The examples verified the promising properties and applications of triazine-linked COFs. A successful synthesis of crystalline CTFs with a large scale will be the focus of future research.

\subsection{Imine linkage}

The polymerization of amines and aldehydes leads to the formation of imine bonds. While the resulting layered COFs with imine linkages were similar to boronic ester COFs, the imine-linked COFs showed higher stability to water, which was significantly different from boron-containing COFs. Imine bonds have been one of the most attractive linkage motifs in COFs owing to the plenty obtainable amine and aldehyde linkers as well as the possibility to construct conjugated $\pi$-systems throughout the whole COF sheets, even though their stability also depends on the incorporated linkers. To date, imine-formation is clearly the most common synthesis strategy employed to build COFs. Early in 2009, the first imine-linked 3D COF (named as COF-300) was reported via the copolymerization of terephthaldehyde (TA) and tetra-(4-anilyl)methane (TAM) by using 1,4-dioxane as the solvent and aqueous acetic acid as catalyst. ${ }^{78}$ The Fourier transform infrared (FT-IR) spectrum of COF-300 exhibited the $\mathrm{C}=\mathrm{N}$ stretch at 1620 and $1202 \mathrm{~cm}^{-1}$, which confirmed the formation of imine bonds. The as-prepared crystalline COF-300 with 5-fold interpenetration was stable up to $490{ }^{\circ} \mathrm{C}$. Furthermore, TAM has been widely used in the construction of 3D COFs. ${ }^{22,79,80}$ Similarly, the first imine-linked 2D COF COF-LZU1 was synthesized through the 
condensation of 1, 4-diaminobenzene with 1, 3, 5triformylbenzene. ${ }^{81}$ The as-prepared COF-LZU1 showed high stability against water and common organic solvent including acetone, dimethyl sulfoxide, tetrahydrofuran, trichloromethane, N,Ndimethylformamide. FT-IR spectrum of COF-LZU1 displayed a strong $\mathrm{C}=\mathrm{N}$ stretching mode of imines at $1618 \mathrm{~cm}^{-1}$. COF-LZU1 was demonstrated to be an ideal platform for metal ions incorporation due to the eclipsed layered-sheet arrangement. Pd/COF-LZU1 catalyst was successfully achieved by post-modification of COF-LZU1 with palladium acetate.

Various building blocks have been involved in imine-based COF formation. ${ }^{82-87}$ For instance, a highly conjugated $\pi$-electron porphyrin unit and its metal derivatives have been largely employed in the construction of functional imine-linked COFs. One study introduced two porphyrin-based COFs, termed COF-66 and COF-366, with the feature of extended planar $\pi$-conjugation. ${ }^{88}$ COF-66 and COF-366 were obtained from the solvothermal reaction of porphyrin and terephthaldehyde (TA) and tetrahydroxy anthracene, respectively, and the formed imine bond was characterized by FT-IR and ${ }^{13} \mathrm{C}$ cross-polarization magic-angle spinning (CP-MAS) NMR spectroscopic techniques. Both COFs exhibited high charge carrier mobility owing to the close intermolecular $\pi-\pi$ distances. A series of porphyrin COFs MP-DHPh COFs with varied H-bonding sites was synthesized via a three-component condensation strategy. Specifically, porphyrin derivatives ( $M P ; \mathrm{M}=\mathrm{H}_{2}, \mathrm{Cu}$, and $\mathrm{Ni}$ ) were used to react with a mixture of TA and dihydroxyterephthalaldehyde (DHTA, H-bonding edges) at different molar ratios $(X=0,25,50,75$, 100). Determined by UV-vis DRS, $\mathrm{H}_{2} \mathrm{P}$-DHPh COF, CuP-DHPh COF, and NiP-DHPh COF possessed narrower band gaps of 1.31, 1.36, and 1.54 $\mathrm{eV}$ compared to that of 1.36, 1.40, and $1.58 \mathrm{eV}$ for the corresponding amorphous MP-Ph polymers, respectively. The $\mathrm{H}_{2} \mathrm{P}-\mathrm{DHPh}$ COF displayed higher photocatalytic singlet oxygen evolution than CuPDHPh COF and NiP-DHPh COF, and the photocatalytic performance of COFs increased with the increasing content of $\mathrm{H}$-bonding site. More recently, a conjugated imine-linked metalloporphyrin COF was prepared through the Schiff-base reaction of $\mathrm{Zn}-5,10,15,20$ tetrakis(4-aminophenyl)-21H,23H-porphyrin (Zn-TAPP) and Cu5,10,15,20-tetrakis(4-formylphenyl)-21H,23H-porphyrin (Cu-TFPP) in the presence of $n$-butanol, $o$-dichlorobenzene and aqueous acetic acid. The resulting $\mathrm{ZnCu}$-Por-COF possessed effective $\pi$-conjugation and high charge-transfer transition.

Interestingly, COFs with two types of covalent linkage was realized by orthogonal (interference-free) reaction strategy. Binary NTU-COF-1 with both boroxine ring and imine group was constructed from the copolymerization of 1,3,5-tris(4-aminophenyl)-benzene (TAPB) and 4-formylphenylboronic acid (FPBA), in which possessed ditopic units of aldehyde and boronate. As indicated by FT-IR spectra, the appearance of B-O stretching bands $\left(1336 \mathrm{~cm}^{-1}\right.$ and $\left.1305 \mathrm{~cm}^{-1}\right)$, $\mathrm{B}-\mathrm{C}$ band $\left(1221 \mathrm{~cm}^{-1}\right), \mathrm{B}_{3} \mathrm{O}_{3}$ band $\left(711 \mathrm{~cm}^{-1}\right)$ and a strong $\mathrm{C}=\mathrm{N}$ band $\left(1627 \mathrm{~cm}^{-1}\right)$ verified the existence of $\mathrm{B}_{3} \mathrm{O}_{3}$ rings and imine linkage. Likewise, ternary NTU-COF-2 was successfully synthesized based on TAPB, FPBA, and HHTP with the formation of $\mathrm{C}_{2} \mathrm{O}_{2} \mathrm{~B}$ boronate ring and imine group. Accordingly, there are two paths for the design of bifunctional linkages. First, one of the building units possess at least two functional moieties, which enables the simultaneous reactions of co-condensation and self-condensation with other functional building blocks, such as TATTA-FPBA COF (TATTA: 4,4', 4' ${ }^{\prime \prime}(1,3,5-$ triazine-2,4,6-triyl)trianiline) and NTU-COF-1. Second, three functional building blocks were employed, and at least one of them has two different functional moieties to enable two non-interfering co-condensation reactions, like NTU-COF-2 and HHTP-FPBA-TATTA COF.

\section{4. $\beta$-ketoenamines linkage}

Improving the stability of COFs is of vital importance pertaining to their applications. Banerjee et al. put forward a two-step strategy to fabricate COFs with high stability when subjected to boiling water, acids and strong bases. ${ }^{89}$ Specifically, TpPa-1 and TpPa-2 with ketoenamine linkage were realized by the condensation of $1,3,5$ triformylphloroglucinol (Tp) with p-phenylenediamine ( $\mathrm{Pa}-1)$ or 2,5dimethyl-p-phenylenediamine ( $\mathrm{Pa}-2)$, in which Tp possess hydroxyl groups adjacent to the formyl groups (scheme 1). Two steps have been involved in COFs formation that is the crystalline framework formed based on the reversible Schiff base reaction, and enhanced stability originated from irreversible enol-to-keto tautomerization. The structure of as-prepared TpPa-1 and TpPa-2 maintained integrity in boiling water and acid, and TpPa-2 was also stable in a basic medium. Notably, $\beta$-ketoenamines linked COFs usually feature less crystalline compared to their imine counterparts as a result of irreversible procedure that error correction might be hindered in COF lattice. ${ }^{90,91}$

Understandably then, the remarkable chemical stability endows $\beta$-ketoenamines linked COFs with exceptional potential for diverse applications such as photocatalytic reaction. Moreover, keto functionalities present in the $\beta$-ketoenamine core could help to enhance the lifetime of the excited triplet state. ${ }^{92}$ For example, two chemical stable $\beta$-ketoenamine COFs were prepared for photocatalytic hydrogen production..$^{93}$ The designed TP-EDDA COF bearing acetylene functional groups was constructed from $\mathrm{Tp}$ and 4,4'-(ethyne-1,2-diyl)dianiline (EDDA), while Tp-BDDA COF with diacetylene moieties was based on the reaction of Tp and 4,4'-(buta1,3-diyne-1,4-diyl)dianiline (BDDA). The appearance of characteristic signals corresponding to $\mathrm{C}=\mathrm{C}$ and $\mathrm{C}-\mathrm{N}$ bonds at $\sim 1451$ and $\sim 1251$ $\mathrm{cm}^{-1}$ confirmed the formation of $\beta$-ketoenamine functionalities. A much higher photocatalytic hydrogen evolution rate of TP-BDDA (324 $\pm 10 \mu \mathrm{mol} \mathrm{h}^{-1} \mathrm{~g}^{-1}$ ) was observed compared to that of TP-EDDA $\left(30 \pm 5 \mu \mathrm{mol} \mathrm{h}^{-1} \mathrm{~g}^{-1}\right)$. Similarly, thioether-functionalized Thio-COF was fabricated via the acid-catalyzed reaction of Tp with thioether substituted diamine, which was highly stable toward the water and common organic solvents (acetone, dichloromethane, ethanol, and tetrahydrofuran, etc.). ${ }^{94}$ The introduction of the thioether group was beneficial for metal deposition and nanoparticle growth, paving the way for various applications, including optical and electronic devices.

In addition, Michael's addition-elimination strategy can also be used to construct $\beta$-ketoenamine linked COFs. ${ }^{95} \mathrm{~A}$ series of COFs were fabricated in a one-step process via the reaction of aromatic amines with di- and tritopic ketoenols. The disappearance of the $\mathrm{N}-$ $\mathrm{H}$ and C-N stretching at 3470,3420 , and $1206 \mathrm{~cm}^{-1}$ together with the appearance of a new C-N band at $1200 \mathrm{~cm}^{-1}$ in FT-IR spectra 
confirmed the formation of $\beta$-ketoenamine linkage. The obtained $\beta$ ketoenamine linked COFs exhibited improved hydrolytic stability owing to the intramolecular hydrogen bonding. The electron delocalization in these COFs generated a narrower band gap and reversible electrochemical doping. Moreover, a wide range of nucleophilic and electrophilic building units can be employed to form this kind of COFs.

\subsection{Hydrazone Linkage}

Reversible condensation of hydrazides with aldehyde building unit yields a crystalline hydrazone-linked structure, which offers the possibility of designing new linkages for COF synthesis. The first two hydrazone-linked COFs, COF-42 and COF-43, were reported in 2011, which were assembled via reversible dehydration of 2,5diethoxyterephthalohydrazide and 1,3,5-triformylbenzene (TFB) or 1,3,5-tris(4-formylphenyl)benzene under solvothermal condition. ${ }^{96}$ $2 \mathrm{D}$ trigonal layers were formed originating from the coplanar feature of hydrazone moiety and aromatic rings. The hydrazones remained the integrity even when COF-43 was submerged into solvents $\mathrm{H}_{2} \mathrm{O}$, dioxane, and dimethyl formamide. ${ }^{97}$ Moreover, the hydrazonelinked COFs have relatively weak interlayer interactions, such that they can be exfoliated into few-layer 2D polymers under mild conditions.

The high robustness and easy processible nature of hydrazone COFs make them popular in various applications. ${ }^{98,99}$ The first visiblelight-active COF was designed and prepared based on hydrazone linkage with the copolymerization of 2,5-diethoxyterephthalohydrazide (DETH) and 1,3,5-tris-(4-formylphenyl)triazine (TFPT). ${ }^{39}$ In the presence of Pt, the system produced 230-1970 $\mu \mathrm{mol} \mathrm{h}^{-1} \mathrm{~g}^{-1}$ of hydrogen. Later, a hydrazone-linked TFBCOF was constructed from TEB and 2,5dimethoxyterephthalohydrazide with a BET surface area of $1501 \mathrm{~m}^{2}$ $\mathrm{g}^{-1}$, which can be used as photocatalyst for cross-dehydrogenative coupling reactions. ${ }^{100}$ Another two hydrazone COFs with rich hydroxy units were synthesized using water and then incorporated with Co" to investigate their Lewis acid catalytic activity. ${ }^{96}$ As a result, the metallated COFs were effective in catalyzing the cyanosilylation reactions of various aldehydes.

\subsection{Azine linkage}

The first azine-linked COF was synthesized by the condensation of 1,3,5,8-tetrakis(4-formylphenyl)pyrene with hydrazine. ${ }^{101}$ For azine linkage, hydrazine acted as a common building block to react with diverse aldehydes, which enables the formation of various functional COFs. ${ }^{102,} 103$ For example, the visible-light-involved hydrogen generation from water can be achieved by the adjustment of COF structure. Three numbers of water- and photo-stable azine-based $\mathrm{N}_{\mathrm{x}^{-}}$ COFs $(x=0,1,2,3$, represent the number of nitrogen in central aryl ring) were synthesized by the polymerization of hydrazine and triphenylarene aldehydes. ${ }^{104}$ Raman and FT-IR spectra were employed to confirm the presence of azine $\mathrm{C}=\mathrm{N}$ linkage. As demonstrated, the photocatalytic hydrogen evolution was enhanced with the increased nitrogen content. Similarly, another series of azine-linked COFs with varied nitrogen atoms in the peripheral aryl ring was prepared for the investigation of photocatalytic hydrogen evolution. ${ }^{105}$ The results suggested that even the very slight changes at the molecular level have a huge influence on the nanoscale morphology, atomic-scale structure, and optoelectronic properties, thereby causing significant differences in the capability of photocatalytic hydrogen production.

\subsection{Imide-based linkage}

In addition, a series of crystalline polyimide (PI) COFs, donated as PICOFs, was fabricated via reversible imidization reaction. ${ }^{106}$ Simply by extending building molecules, the large pore size of as-prepared PICOFs could be tuned. PI-COF- 3 with a pore size of $5.3 \mathrm{~nm}$ and BET surface area of $2,346 \mathrm{~m}^{2} \mathrm{~g}^{-1}$ was designed and prepared by imidization condensation of 1,3,5-tris[4-amino(1,1-biphenyl-4$\mathrm{yl})$ ]benzene (TABPB) with pyromellitic dianhydride (PMDA) in a mixed solvent of mesitylene, $\mathrm{N}$-methyl-2-pyrrolidone (NMP), and isoquinoline. The presence of $\mathrm{C}=\mathrm{O}$ stretches at 1779 and $1718 \mathrm{~cm}^{-1}$ and $\mathrm{C}-\mathrm{N}-\mathrm{C}$ stretching vibration at $1382 \mathrm{~cm}^{-1}$ in $\mathrm{FT}-\mathrm{IR}$ spectra revealed the formation of imide linkage in PI-COF-3. By linking the linear building unit PMDA and triangular building unit TABPB, PI-COF-3 was formed like a boron nitride net. ${ }^{107}$ The material remained stable in water and common organic solutions, such as acetone, ethanol, $\mathrm{m}$ cresol, N,N-dimethylformamide, tetrahydrofuran, and hexanes. Notably, the large dye molecules can also be incorporated into PICOF-3 with distinctive applications. Other functional building blocks have been utilized in the formation of imide-based COFs, such as PMDA and 1,3,5,7-tetraaminoadamantane (TAA) or tetra(4aminophenyl)methane (TAPM), ${ }^{108}$ PMDA and tetraminobenzoquinone (TABQ), ${ }^{109}$ and perylenetracarboxylic dianhydride (PTCA) and tetra(4-aminophenyl) porphyrin (TAPP). ${ }^{110}$

\subsection{Other Linkages}

Besides the above-mentioned linkages, other linkages have also be used in COF fabrication such as carbamate linkage, ${ }^{111}$ borosilicate linkage, ${ }^{112}$ phenazine linkage, ${ }^{113}$ and squaraine linkage. ${ }^{114}$ For example, a 3D borosilicate-linked COF was first synthesized by condensation of tetra(4-dihydroxyboryl-phenyl)methane, tertbutylsilane triol, and ${ }^{\mathrm{t}} \mathrm{BuSi}(\mathrm{OH})_{3} .{ }^{112}$ The as-prepared $\mathrm{COF}$ (named COF-202) possessed a BET surface area of $2690 \mathrm{~m}^{2} \mathrm{~g}^{-1}$ and high stability. Later, A crystalline borazine-linked COFs named BLP-2(H) was prepared by thermal decomposition of 1,3,5-(p-aminophenyl)benzene-borane. ${ }^{115}$ This as-prepared COF showed a BET surface area of $1178 \mathrm{~m}^{2} \mathrm{~g}^{-1}$. A squaraine-linked COF with zigzagged confirmation was achieved by the copolymerization of copper(II) 5,10,15,20tetrakis(4-aminophenyl)porphyrin (TAP-CuP) and squaric acid (SQ). ${ }^{114}$ As indicated in FT-IR spectra, $\mathrm{C}=\mathrm{O}$ bond $\left(1595 \mathrm{~cm}^{-1}\right)$ was formed with a blue-shift compared with SQ $\left(1579 \mathrm{~cm}^{-1}\right)$ due to the extended $\pi$-conjugation of the COF. This CuP-SQ COF with visible light absorption could act as an effective photocatalyst for singlet oxygen generation.

In addition, two crystalline benzobisoxazole-linked (BBO) COFs were prepared by the condensation of 2,5-diamino-1,4-benzenediol dihydrochloride (DABD) with TFB or 1,3,5-tris(4formylphenyl)benzene (TFPB) under the catalysis of cyanide. ${ }^{116} \mathrm{~A}$ three-step mechanism was proposed to explain the BBO linkage formation: (1) a phenolic imine linked intermediate was first formed, (2) then ring closure took place with the addition of cyanide to the imine and a benzoxazoline intermediate appeared, and finally (3) the 
benzoxazoline intermediate was oxidized under air, thereby promoting the BBO linkage formation. ${ }^{117}$ The resulting BBO-COF 1 and BBQ-COF 2 displayed excellent water stability and the high surface area of $891 \mathrm{~m}^{2} \mathrm{~g}^{-1}$ and $1106 \mathrm{~m}^{2} \mathrm{~g}^{-1}$, respectively. In another study, a room-temperature solution-phase reaction was employed to synthesize an azodioxy-linked COF (POR-COF) with $\mathrm{I}_{2}$-dopingenhanced photo-current generation. ${ }^{118} \mathrm{~A}$ series of spiroboratelinked ionic COFs (ICOFs) were synthesized with a high BET surface area up to $1259 \mathrm{~m}^{2} \mathrm{~g}^{-1}$, constructed from the transesterification of diol and trimethyl borate. ${ }^{119}$ Recently, the unsubstituted olefinlinked COF (COF-107) was first synthesized by Aldol condensation of 4,4'-biphenyldicarbaldehyde (BPDA) and 2,4,6-trimethyl-1,3,5triazine (TMT) (Scheme 2). ${ }^{26} \mathrm{FT}-\mathrm{IR}$ and ${ }^{13} \mathrm{C}$ CP-MAS spectroscopy were utilized to verify the formation of $-\mathrm{CH}=\mathrm{CH}$ - linkage. The as synthesized COF-701 possesses a BET surface area of $1715 \mathrm{~m}^{2} \mathrm{~g}^{-1}$ and high chemical robustness owing to the existence of unsubstituted olefin linkage.

As discussed above, various covalent linkage motifs have been designed relating to the COF formation. Different linkages lead to different structures and properties, which further affects the specific applications. Compared to triazine-based COFs, imine-linked COFs display more diverse structural regularity and enhanced crystallinity. Superior to the boron-containing COFs in terms of hydrolytic stability, imine-linked and other nitrogen-containing COFs are more popular. And the Lewis basic nitrogen-containing backbone allows for the incorporation of various metal ions to act as active sites for catalysis. While COF based on imines, hydrazones, and azines are insensitive toward the water and most organic solvents, COFs with $\beta$ ketoenamines linkages are more stable. Moreover, imines, phenazines, benzobisoxazoles and olefns also represent an attractive linking type related to in-plane conjugation, which benefits the light absorption and charge carrier transfer. Certainty, as for a specific application, all related properties should be taken into consideration. Despite the rapid development of various linkages, the mechanism study of COF formation is still in critical need.

\section{Morphology of COFs}

One of the most common design strategies for optimizing photocatalytic performance is morphology control. Abundant building blocks and functional covalent linkages endow COFs with a designable structure. Indeed, many studies have been done to investigate the features of COFs with special structures, including OD structures (e. g. nanoparticles), 119, 120 1D structures (e. g. nanofibers, nanowires and nanorods), 121, 122 2D structures (e. g. thin films and nanosheets), ${ }^{123,124}$ and 3D structures (e. g. hollow sphere, core-shell, bouquet-shape). ${ }^{125,} 126$ The morphology and structure investigations of COFs are of great importance for their photocatalytic performance. In this section, the synthesis and photocatalytic properties of COFs on the morphologies were discussed.

\subsection{0-dimensional structures}

OD-structural materials are considered as promising photocatalysts due to the large surface area. However, their photocatalytic efficiency still suffers from low efficiency due to the large agglomeration. In most cases, the monomers of COF are partially soluble in reaction solvents, leading to a heterogeneous growth condition, thereby making it hard to understand the crystallization process. Currently, most of the reported COFs are synthesized with poor controlled morphology and final form, forming insoluble and unprocessable aggregates. Recently, a strategy of homogeneous polymerization was put forward to avoid the irreversible aggregation and precipitation of crystallites, providing stable colloidal suspensions of COF nanoparticles. ${ }^{127}$ By adding a certain amount of $\mathrm{CH}_{3} \mathrm{CN}$ in a conventional solvothermal mixture of COF-5, translucent solution with nanoparticles was obtained. $\mathrm{CH}_{3} \mathrm{CN}$ was demonstrated to stabilize the discrete crystallites and inhibit their aggregation in solution (Fig. 3a and 3b). Further investigation demonstrated that the interaction of the COF and nitrile functional group was responsible for the nanoparticle formation. Interestingly, the realtime growth of individual nanoparticles was observed using variabletemperature liquid cell transmission electron microscopy (VT-LCTEM) imaging (Fig. 3c). These stable porous nanoparticles with the functional internal surface were capable of site-isolated catalysis. Besides, a two-step approach was utilized to further control the formation of 2D COFs, which provided single-crystalline and micrometer-sized particles. When heating the COF-5 colloidal suspension, separated solutions of HHTP and PBBA were simultaneously injected, generating COF-5 nanoparticles ranging from $30 \mathrm{~nm}$ to $400 \mathrm{~nm}$. To verify the generality of this strategy, the other two boronates ester-linked COF-10 and TP-COF were also studied. And later, the research was further expanded to the iminelinked COF. Colloidal TAPB-PDA COF nanoparticles were obtained by adding $\mathrm{MeCN}$ in the reaction system, which possessed a high BET surface area of $2070 \mathrm{~m}^{2} \mathrm{~g}^{-1}$. Similarly, considering the narrow range of nanoparticle size, separated solutions of TAPB and PDA were injected simultaneously to TAPB-PDA COF colloids solution. And the morphologies of the particles varied with the different monomer addition rates (Fig. 11).

Nanoparticles with favorable surface speciation are deemed to display excellent photocatalytic activity compared with their bulkphase counterparts. In addition, it is probable to improve the redox potential of conduction band electrons and valence-band holes by changing the particle size. ${ }^{128,129}$ By reducing the particle size, the conduction band and valence band could be shifted to counterparts due to the quantum confinement effect, thus improving the redox potential of photogenerated electrons and holes. However, the study of COF photocatalysts with 0-dimensional structure remains challenging.

\subsection{1-dimensional structures}

1D structures such as nanofibers, nanoribbons, and nanowires have attracted considerable attention due to their high surface-to-volume ratio. ${ }^{130}$ The study of COF morphology related to $1 \mathrm{D}$ structures is of great value. Up to date, solvothermal synthesis, vapor-assisted solidstate synthesis, and bottom-up microfluidic synthesis have been used to fabricate crystalline COF fibers. For example, novel crystalline COF nanofibers were fabricated by the solvothermal method based on the condensation of 2,4,6-tris(4-aminophenyl)-pyridine (TAPP) with 2,6-Dihydroxynaphthalene-1,5- dicarbaldehyde (DHNDA) at 
$180^{\circ} \mathrm{C}$. The as-prepared COF was formed as uniform nanofibers with lengths of up to tens of micrometers. Interestingly, it was indicated the morphology transformed from irregular nanoparticles to uniform nanofibers with increased crystallinity, which may be ascribed to the dissolution-recrystallization process. This transformation enabled the fabrication of COF nanohybrid with excellent optical and electrical properties. Similarly, nanofibers could also be obtained via vapor-assisted solid-state synthesis. Different from the solvothermal synthesis, the polycondensation of TAPP and DHNDA was carried out by putting the mixture of monomers in solvent vapor at $120^{\circ} \mathrm{C}$ for 48 h. In this method, only a small quantity of solvent vapors was needed, and the nanofibrous morphology was varied with the reaction time and the solvent vapor composition.

Likewise, g- $\mathrm{C}_{18} \mathrm{~N}_{3}$-COF with fibrillar morphology was synthesized by Knoevenagel condensation reaction of 1,4-diformylbenzene (DFB) and 2,4,6-trimethyl-1,3,5-triazine (TMTA) (Fig. 3d and 3e). The ultraviolet-visible diffuse reflectance spectroscopy (UV-vis DRS) displayed that the absorption band edge of $\mathrm{g}-\mathrm{C}_{18} \mathrm{~N}_{3}-\mathrm{COF}$ was at 450 $\mathrm{nm}$, indicating a strong visible-light harvesting. And $\pi$-conjugated $\mathrm{g}$ $\mathrm{C}_{18} \mathrm{~N}_{3}$-COF with an average lifetime of $7.25 \mathrm{~ns}$ revealed the suppressed photogenerated electron-hole recombination. With ascorbic acid as a sacrificial agent and Pt as a co-catalyst, an average $\mathrm{H}_{2}$ production rate of $292 \mu \mathrm{molg}^{-1} \mathrm{~h}^{-1}$ was achieved over g- $\mathrm{C}_{18} \mathrm{~N}_{3}$-COF. In addition, COFs bearing Tp and melamine (MA) building units with visible-light-response features were synthesized as exfoliated thin ribbon-like and interwoven thread-shaped structures under different conditions (catalyst-assisted, solvent-assisted, and liquid-free) by ball milling. Compared to the thread-shaped COF, the optical absorption edge of ribbon-like COF displayed a red-shift, enhancing solar utilization efficiency, and therefore leading to a higher photocatalytic degradation rate of phenol. These findings suggested that the morphology affected the photocatalytic activity of COFbased materials, which may be related to the aggregation behavior, dispersity, and incident light-harvesting capability in water.

\subsection{2-dimensional structures}

The optical, photoelectrical and photochemical features of the materials could be affected directly or indirectly if their morphology and structure are changed. In addition to the $\mathrm{OD}$ and $1 \mathrm{D}$ structures, 2D structures like thin films and few-layered nanosheets have also been widely studied in the photocatalytic process. ${ }^{131,132}$ Indeed, the high smoothness and aspect ratio along with the short travel distance of the photoexcited carriers render the thin films with high photocatalytic performance. ${ }^{133,} 134$ In recent years, various methods have been utilized to synthesize COF thin films as free-standing forms or deposited on specific substrates, such as mechanical delamination, ${ }^{90,} 135$ solvent-assisted exfoliation, ${ }^{136,137}$ solvothermal synthesis ${ }^{138}, 139$ and interfacial synthesis. ${ }^{140,} 141$ Among them, solvothermal synthesis is widely used because it is simple and straightforward. For example, TT-COF thin films with a $200 \mathrm{~nm}$ thickness were prepared on the cleaned glass substrate by simply immersing the substrate in the solution of bulk TT-COF synthesis. ${ }^{142}$ As demonstrated by grazing incidence $X$-ray diffraction (GIXRD), the growth of 2D TT-COF thin films was parallel to the surface of the glass substrate, which indicated an ordered charge transfer pathway.
Greatly enhanced photoresponse speed was observed in the wellordered COF thin film.

In another study, BDT-ETTA COF based on amine-functionalized 1,1',2,2'-tetra-p-aminophenylethylene (ETTA) and donor-type benzo[1,2-b:4,5-b']-dithiophene-2,6-dicarboxaldehyde (BDT) was grown on indium tin oxide (ITO) substrate to yield BDT-ETTA COF thin films. The obtained COF thin films displayed strong visible light absorption with a threshold of $c a .550 \mathrm{~nm}$ and a band gap of $2.47 \mathrm{eV}$, indicating a photoactive potential. The results suggested that the BDT component could be the reason for the photoactivity, and the oriented COF thin films as the precondition amplified the photoresponse and improved the stability. A new synthetic method was employed by directly condensing 3,4,9,10perylenetetracarboxylic diimide (PDI) and cyanuric chloride (CC) to yield a CTF film photocatalyst. CTF film with excellent photocatalytic activity showed an enhanced NADH regeneration of $75.88 \%$ and $\mathrm{HCOOH}$ production of $204.14 \mu \mathrm{m}$. Also, ultrathin 2D porphyrin nanodisks with enhanced photocatalytic activity were prepared by COF exfoliation via axial ligands incorporation. Porphyrin-containing COF DhaTph (Dha: 2,5-dihydroxyterephthalaldehyde, Tph: 5,10,15,20-tetrakis(4-aminophenyl)-21H,23H-porphyrin) was exfoliated by simultaneously incorporating 4-ethylpyridine and copper $(\mathrm{Cu})$ ions ligands into the porphyrin center to yield e- $\operatorname{CON}(\mathrm{Cu}$, epy) (Fig. $4 a$ and $4 b$ ). The resulting e-CON was further incorporated with Pt nanoparticles and reduced-graphene oxide (RGO) to obtain composite materials e-CON(Cu, epy)/Pt/RGO for photocatalytic reaction (Fig. 4c). Compared with DhaTph/Pt/RGO, an enhanced visible/NIR-light-induced hydrogen evolution of e-CON(Cu, epy)/Pt/RGO system was observed owing to the higher surface area between e-CON and Pt/RGO. The abovementioned results demonstrated that the 2-dimensional COF thin films and nanosheets with broad light absorption, optical band gap, and efficient charge separation and transfer have great potential for photocatalytic activity improvement.

\subsection{3-dimensional structures}

COFs with 3D structures are synthesized mainly by heterogeneous nucleation growth, ${ }^{143,}, 144$ template-directed approach, ${ }^{125,} 145,146$ selfassembly strategy, ${ }^{144,147,148}$ multiple-linking-site strategies. ${ }^{149}$ In the study of Zhao and co-workers, methyl groups were introduced into triptycene tricatechol (TPTC) to increase the space between monolayers, thus further weaken the $\pi-\pi$ stacking interactions. As a result, the floating film-like structure was obtained by solvothermal condensation of TPTC and BDBA or 4, 4'-biphenyldiboronic acid (BPDBA). Interestingly, mono-layered and multi-layered hollow spherical structures were found to exist. Different from stacking structures obtained from conventional solvothermal reactions, the condensation of TPTC with boronic acids first produced singlemolecule-layered 2D frameworks. As the polymerization time progressed, the monolayers occurred curly and tended to form mono-layered hollow spheres driving by surface energy reduction. And the layers would also enwrap the mono-layered spheres to generate uniform multi-layered hollow microspheres. While the abovementioned hollow spherical COF showed poor crystallinity, a crystalline hollow spherical COF, namely DhaTab, was synthesized 
based on 1,3,5-tris (4-aminophenyl)benzene and 2,5dihydroxyterephthalaldehyde by self-template synthesis. Two steps were involved in the formation of a hollow spherical structure: first, COF-DhaTab with rod-like morphology was formed initially in $12 \mathrm{~h}$, and then randomly self-assembled into curly or dense spheres (Fig. 5a). An inside-out Ostwald ripening was invoked in the formation of hollow spherical morphology for the next 24 has the crystallites in the inner part of the sphere have got higher surface energy than those on the outer surface, and crystallites on the sphere wall fused to produce a smooth surface with the time increased (Fig. 5b and 5c).

In addition, a template-assisted synthesis method has also been used in constructing hollow nanostructures. For example, Hollow $\mathrm{TpPa}$ COF was designed and synthesized with the assist of $\mathrm{ZnO}$ nanorod template. First, $p$-phenylenediamine $(\mathrm{Pa})$ and $\mathrm{Tp}$ were dehydrated in the presence of $\mathrm{ZnO}$ nanorods, and then the $\mathrm{ZnO}$ nanorods were removed by treating the produced hybrid materials with acid $(1 \mathrm{~N} \mathrm{HCl})$ for $24 \mathrm{~h}$, leading to the formation of hollow TpPa nanostructures with the inner and outer diameters of $d=$ (70-130) $\mathrm{nm}$ and $d=(60-100) \mathrm{nm}$, respectively (Fig. 17).Another imine-linked TpBD COF containing Tp and benzidine (BD) building blocks were directly grown on $\mathrm{Fe}_{3} \mathrm{O}_{4}$ by a solvothermal method to form a coreshell structural TpBD@ $\mathrm{Fe}_{3} \mathrm{O}_{4}$. The hollow TpBD was further obtained by etching the $\mathrm{Fe}_{3} \mathrm{O}_{4}$ core in $\mathrm{HCl}$ solution, resulting in a shell thickness of $c a .50 \mathrm{~nm}$. These references could offer an important process for the construction of COF-based photocatalysts. The hollow structures obtained from a template-assisted method possess ordered and uniform cavities simply by controlling the template diameter. Hollow structure with controlled porosity reduces diffusion length and improves contact of active sites with reactants. ${ }^{150,151}$ Moreover, the multiple reflections within the hollow cavity are benefit for the efficient light utilization, producing more photogenerated charge carriers. ${ }^{152,153}$

Apart from hollow morphology, flower-shaped morphology was also obtained by controlling the synthetic conditions of TpPa-1 and TpPa-2 COFs. ${ }^{89}$ Each flower was assigned to the aggregation of sheetlike petals with 1-3 $\mu \mathrm{m}$ in lengths as a result of the $\pi-\pi$ stacking of COF layers. Specifically, the petals of TpPa-1 with spike-like tips grown out from a core, while TpPa-2 with longer and broader petals showed plate-like structure. Similar morphology has also been formed in Tp-Azo COF, which aggregated petals with an average length of $40-50 \mathrm{~nm}$ to obtain the flower-like structure. Later, a bouquet-shaped magnetic TpPa-1 was successfully fabricated through a room-temperature solution-phase approach. Initially, TpPa-1 was covered on the surface of clustered $\mathrm{Fe}_{3} \mathrm{O}_{4} \mathrm{NPs}$, and then it began to grow thread-like structure. When the formation time reached to $30 \mathrm{~min}$, the branch type TpPa-1 interconnected each other to develop a bouquet-like morphology. Magnetic TpPa-1 with enhanced reactant and active site accessibility exhibited potential for photocatalysis due to its large specific surface area, high porosity and supermagnetism.

\section{Strategies for enhancing the photocatalytic activity of COFs}

\subsection{Functional building blocks incorporation}

One of the most attractive characteristics of COFs related to photocatalysis is their regular structures with unlimited building blocks, which can be applied to various reaction conditions. Based on reticular chemistry, COFs allow a predesigned pathway for precise controlling over their structures and properties by choosing different linkers as well as different building units containing function groups or side chains. ${ }^{110,}{ }^{154-158}$ Up to date, functional building blocks incorporation is the most widely used strategy for improving the photocatalytic performance of COFs. For example, a series of azinelinked $\mathrm{N}_{\mathrm{x}}$-COF photocatalysts were synthesized by selecting hydrazine as the linker and triphenylarene aldehydes as the nodes, in which the nitrogen atoms of central aryl ring in aldehyde units varied from 0 to 3 (Fig. 6a and 6b). ${ }^{104}$ Replacing the carbon atoms with nitrogen atoms led to the formation of different central rings namely phenyl $(\mathrm{N}=0)$, pyridl $(\mathrm{N}=1)$, pyrimidyl $(\mathrm{N}=2)$, and triazine $(N=3)$, showing the increased planarity due to the decreased dihedral angle between peripheral phenyl rings and the central aryl ring. Consequently, increased crystallinity was observed as a result of the increasing nitrogen contents (Fig. 6c). On the other hand, the optical band gap changed a little, as a higher degree of conjugation with increased planarity was compensated by the increased electron-deficient of the central aryl ring, which made the $\mathrm{N}_{\mathrm{x}}$-COF ensemble an ideal model platform for photocatalysis experiment. Visible-light-induced hydrogen evolution with $\mathrm{N}_{\mathrm{x}}$-COF photocatalyst was investigated with Pt as a co-catalyst and TEOA as a sacrificial electron donor. The increase of hydrogen evolution in the test period of $8 \mathrm{~h}$ was observed with the replacement of $\mathrm{C}-\mathrm{H}$ by $\mathrm{N}$ in the central aryl ring in the COF platform, and the average amount of hydrogen evolved from the most active $\mathrm{N}_{3}$-COF was $1703 \mu \mathrm{mol} \mathrm{h}{ }^{-1} \mathrm{~g}^{-1}$ (Fig. 6d). Besides, $\pi$-conjugated trans-disubstituted $\mathrm{C}=\mathrm{C}$ linked COFs (termed $\mathrm{g}-\mathrm{C}_{\mathrm{x}} \mathrm{N}_{\mathrm{y}}$-COFs) with different properties were designed and synthesized based on the Knoevenagel condensation of 3,5-dicyano2,4,6-trimethylpyridine (DCTMP) with linear 4,4"'-diformyl-pterphenyl (DFPTP), 4,4'-diformyl-1,1'-biphenyl (DFBP), or trigonal 1,3,5-tris(4-formylphenyl)benzene (TFPB), which yielded $\mathrm{g}^{-} \mathrm{C}_{40} \mathrm{~N}_{3}$ $\mathrm{COF}, \mathrm{g}-\mathrm{C}_{31} \mathrm{~N}_{3}-\mathrm{COF}$, and $\mathrm{g}-\mathrm{C}_{37} \mathrm{~N}_{3}-\mathrm{COF}$, respectively. As demonstrated by ultraviolet/visible diffuse reflectance spectroscopy (UV/vis DRS), g- $\mathrm{C}_{40} \mathrm{~N}_{3}$-COF showed a significant red-shift of absorption edge compared with g- $\mathrm{C}_{31} \mathrm{~N}_{3}-\mathrm{COF}$ and $\mathrm{g}-\mathrm{C}_{37} \mathrm{~N}_{3}-\mathrm{COF}$, indicating a stronger ability of light-harvesting in the visible region; and g- $\mathrm{C}_{40} \mathrm{~N}_{3}-\mathrm{COF}$ with a smaller optical band gap (2.36 eV) was observed as compared to g$\mathrm{C}_{31} \mathrm{~N}_{3}$-COF $(2.40 \mathrm{eV})$ and $\mathrm{g}-\mathrm{C}_{37} \mathrm{~N}_{3}$-COF $(2.52 \mathrm{eV})$. Time-resolved fluorescence decay spectroscopy was also used to characterize the excitation recombination with the information of the average lifetime of photo-excited electrons. As a result, g- $\mathrm{C}_{40} \mathrm{~N}_{3}-\mathrm{COF}$ exhibited the most extended fluorescence lifetime (3.31 ns) due to the charge separation in the extended $\pi$-conjugated structure. These findings along with other optical and electronic characterizations (Mott-Schottky measurement, photocurrent tests, etc.) suggested that $\mathrm{g}-\mathrm{C}_{40} \mathrm{~N}_{3}$-COF permitted the effective photogenerated electronhole transfer, thereby showing great potential for photocatalytic water splitting. A remarkable $\mathrm{H}_{2}$ production rate of $\mathrm{g}-\mathrm{C}_{40} \mathrm{~N}_{3}-\mathrm{COF}$ $\left(4120 \mu \mathrm{molh}^{-1} \mathrm{~g}^{-1}\right)$ was observed in the presence of Pt as a co- 
catalyst and TEOA as a sacrificial agent, which was much higher than g- $\mathrm{C}_{31} \mathrm{~N}_{3}-\mathrm{COF}\left(542 \mu \mathrm{molh}^{-1} \mathrm{~g}^{-1}\right)$ and g- $\mathrm{C}_{37} \mathrm{~N}_{3}-\mathrm{COF}\left(396 \mu \mathrm{molh}^{-1} \mathrm{~g}^{-1}\right)$ Therefore it is indicated that the photocatalytic performance of COFs can be improved by precisely selecting of building units.

Various functional building blocks such as triazine, sulfone, pyrene, benzothiadiazole, and thiophene, have been utilized for constructing COF photocatalyst with high performance. For example, diacetylene-bridged COFs were of great interest due to their highly conjugated structures, accelerated charge career mobility, and accessible active sites for facile migration of photogenerated excitons to the surface. Highly porous and chemically stable acetylene $(-C \equiv C-)$ and diacetylene $(-C \equiv C-C \equiv C-)$ functionalized $\beta$ ketoenamine COFs, TP-EDDA and TP-BDDA, were prepared to serve as photocatalysts for hydrogen generation from water. To analyse the effect of acetylene and diacetylene moieties on optical and catalytic properties, an isoreticular COF with similar pore apertures constituted from terphenylene edges (TP-DTP COF, DTP: 4,4"diamino-p-terphenyl) was synthesized. Optical band gaps determined from Tauc plots were 2.42, $2.34 \mathrm{eV}$ and $2.31 \mathrm{eV}$ for TPDTP, TP-EDDA and TP-BDDA, respectively, which were ideal for photocatalytic water splitting requiring a minimum band gap of $\sim 1.8$ $\mathrm{eV}$. Photocatalytic hydrogen evolution experiments were conducted by using 10 vol\% TEOA as a sacrificial electron donor and Pt as a cocatalyst. All COFs were tested for long-term (10 h) hydrogen evolution under visible light ( $\geq 395 \mathrm{~nm}$ ). TP-BDDA showed continuous hydrogen evolution over $10 \mathrm{~h}$ with an average rate of $324 \pm 10 \mu \mathrm{mol}$ $\mathrm{h}^{-1} \mathrm{~g}^{-1}$, while TP-DTP and TP-EDDA produced a negligible amount of hydrogen of $20 \pm 5 \mu \mathrm{mol} \mathrm{h} \mathrm{h}^{-1} \mathrm{~g}^{-1}$ and $30 \pm 5 \mu \mathrm{mol} \mathrm{h}^{-1} \mathrm{~g}^{-1}$, respectively. The remarkable apparent quantum efficiency of $1.8 \%$ was obtained on TP-BDDA with $520 \mathrm{~nm}$ incident light, which was very close to the absorbance maxima of the TP-BDDA. These results implied that the conjugated diacetlylene moiety $(-\mathrm{C} \equiv \mathrm{C}-\mathrm{C} \equiv \mathrm{C}-)$ was playing an important role in enhancing the activity for photochemical water reduction. Apart from narrowing the band gap, diacetylene-moieties were also responsible for the facile migration of photogenerated excitons to the surface of photocatalyst concluded from studies on molecular counterparts. In addition, electron acceptor such as benzothiadiazole (BT), and electron donors such as Tris(4aminophenyl)benzene (TPB) and tris-(4-aminophenyl)triazine (TAPT) were employed to construct COFs with tailored band gaps and improved charge separation and transfer. The resultant BT-COFs showed the extended absorption bands ranging from $400 \mathrm{~nm}$ to 800 $\mathrm{nm}$. A narrow band gap of TPB-BT-COF $(2.05 \mathrm{eV})$ was observed as compared to that of TAPT-BT-COF $(2.13 \mathrm{eV})$. The conduction bands of both BT-COFs were more negative than the redox reaction potential of $\mathrm{Cr}(\mathrm{VI})$ to $\mathrm{Cr}(\mathrm{III})$ (1.33 V vs. NHE), indicating the ability of $\mathrm{Cr}(\mathrm{VI})$ reduction. As a result, TPB-BT-COF could reduce $99 \%$ of $\mathrm{Cr}(\mathrm{VI})$ within $75 \mathrm{~min}$ visible light irradiation, and the photoreduction rate of it was faster than that of TAPT-BT-COF.

\subsection{Elemental doping}

Elemental doping is another strategy of modifying the electronic structures and surface properties of semiconductors, thus improving their photocatalytic performance. The element sulfur is known as a promising dopant that can modulate both the optical absorption properties and the electronic structure of organic semiconductor photocatalytic materials. ${ }^{159,} 160$ The sulfur-doped CTF samples were obtained through the annealing treatment of a covalent triazinebased framework (CTF-T1) with sulfur, and were denoted as CTFS $\mathrm{X}$ ( $\mathrm{X}$ $=5,10,20,30) .{ }^{161}$ The photocatalytic activities for hydrogen evolution using CTF-T1 and CTFSx were evaluated by using Pt as a hydrogen evolving co-catalyst and TEOA as an electron donor under visible light irradiation $\left(\lambda \geq 420 \mathrm{~nm}\right.$ ). Compared with the $\mathrm{g}-\mathrm{C}_{3} \mathrm{~N}_{4}$ photocatalyst, CTFS $S_{x}$ showed much better photocatalytic performance, and the highest photoactivity was obtained using CTFS10 which was about 5 times higher than that of CTF-T1. Similarly, other typical non-metal dopants such as -Halogens- have also been utilized for photocatalysis improvement. A series of halogen $(\mathrm{F}, \mathrm{Cl}$ and $\mathrm{Br}$ )-doped CTFs was prepared by thermal treatment of CTF-1 with excessive ammonium halide. ${ }^{162}$ As compared with pristine CTF1, halogen-doped CTF-1 with decreased Nyquist plot diameter and higher photocurrent density revealed the improved efficiency of charge separation and transfer (Fig. 9a and 9b). The optical band gap of CTF-1, CTFF, CTFCl and CTFBr was determined to be 2.94, 2.82, 2.48 and $2.63 \mathrm{eV}$ (Fig. 9d). The narrower band gaps and facilitated electron transfer in the modified $\pi$-conjugated CTF greatly enhanced the photocatalytic $\mathrm{H}_{2}$ evolution rate in the CTFX catalytic system evidenced by 7.1 times higher photocatalytic ability of CTFCl compared to pristine CTF-1 (Fig. 9c).

\subsection{Sensitizer}

Light-harvesting is one of the most important prerequisites for electron-hole generation, which greatly affects the photocatalytic performance. Photosensitizer with intense visible light absorption can be used as a co-catalyst to enhance light absorption and the lifetime of photoinduced electron-hole pairs, thus improving the photocatalytic performance. ${ }^{163,} 164$ The photocatalytic activity of COFs modified with palladium acetate was investigated by using Eosin $Y(E Y)$ as a sensitizer and TEOA as a sacrificial donor. ${ }^{165}$ Isoreticular TpPa-1 and COF-LZU1 were employed to facilitate energy transfer. As demonstrated, while $\mathrm{Pd} 0 / \mathrm{TpPa}-1$ and $\mathrm{Pd} / \mathrm{COF}-\mathrm{LZU} 1$ were not photoactive without $\mathrm{EY}$, they exhibited enhanced photocatalytic $\mathrm{H}_{2}$ evolution with the help of EY. When EY adsorbed visible light, electrons were generated and then transferred from COFs to $\mathrm{Pd}$ active sites for $\mathrm{H}_{2}$ production. Furthermore, 2D COFs with $\pi$-conjugated structures could effectively facilitate the photogenerated electrons transfer, leading to the improved $\mathrm{H}_{2}$ evolution.

\subsection{Hybrid construction}

In addition, hybrid materials with synergistic effects are believed to provide versatile characters for photocatalysis. By carefully design, multicomponent heterojunction materials with improved photocatalytic efficiency could be achieved regarding the promoted charge separation and enhanced charge carrier transfer. COFs-based composites have also been reported to show enhanced photocatalytic activity. ${ }^{166,} 167$ Crystalline COF can serve as an attractive support matrix for nanoparticle loading owing to its remarkable stability, high surface area and porosity. ${ }^{168}$ Highly stable TpPa-2 COF was employed as a support matrix for anchoring CdS nanoparticles. The $\pi$-conjugated COF support was believed to 
enhance the photostability of the loaded CdS nanoparticles and suppress the photogenerated electron-hole recombination, thereby improving the photocatalytic performance. To examine the photocatalytic behavior of the CdS-COF hybrids, visible-light-driven $\mathrm{H}_{2}$ evolution experiments were carried out using $0.5 \mathrm{wt} \% \mathrm{Pt}$ as a cocatalyst, lactic acid as a sacrificial agent. The CdS-COF hybrids showed enhanced $\mathrm{H}_{2}$ evolution compared to bulk CdS. Likewise, CdS nanoparticle-decorated CTF-1 (CdS NPs/CTF-1) were controllably synthesized via a facile one-pot solvothermal method. Due to the Lewis basic nature of well-defined nitrogen sites in triazine units of CTF-1, highly dispersed and size-controlled CdS NPs were obtained and stabilized on the surface of CTF-1 layers. The CdS NPs/CTF-1 assembly showed a higher photocatalytic $\mathrm{H}_{2}$ generation rate than pure CdS and CTF-1 under visible light irradiation. The increased photocatalytic performance was ascribed to the highly dispersed CdS NPs with strong interaction on CTF-1 layers. The strong NP-on-layer interactions between CdS and CTF-1 not only facilitated the photogenerated charge separation but also equipped CdS with a nanosized structure and high stability. In addition, 2D layered $\mathrm{BiOBr}$ is frequently used in photocatalytic environment remediation and energy conversion due to its excellent electrical, optical, and catalytic features. ${ }^{169,} 170$ However, it still suffers from the small surface area, poor light absorption, and high photoinduced electron-hole recombination. Hence, heterojunction based on CTFs and $\mathrm{BiOBr}$ could be developed to enhance photocatalytic activity. It was indicated that $\mathrm{BiOBr} / \mathrm{CTF}-3 \mathrm{D}-2 \%$ possessed much higher degradation performance of tetracycline hydrochloride (TC) and ciprofloxacin (CIP) compared to pure $\mathrm{BiOBr}$ and CTF-3D.

A novel MOF@COF core-shell hybrid material was constructed to possess high photocatalytic performance toward Rhodamine $B$ (RhB) photodegradation. ${ }^{171}$ By virtue of its available amino functional groups and high stability under harsh experiment conditions, $\mathrm{NH}_{2-}$ MIL-68 with 2-aminoterephthalic acid ligands and $\mathrm{InO}_{4}(\mathrm{OH})_{2}$ infinite chains were selected. As depicted in the scheme, $\mathrm{NH}_{2}-\mathrm{MIL}-68$ was first synthesized through solvothermal reaction, and then functionalized by tris(4-formylphenyl)amine (TFPA) molecule to obtain aldehyde-functionalized $\mathrm{NH}_{2}-\mathrm{MIL}-68$, donated as $\mathrm{NH}_{2}$-MIL$68(\mathrm{CHO})$. And TPA-COF was grown on $\mathrm{NH}_{2}-\mathrm{MIL}-68(\mathrm{CHO})$ surface by covalent linking tris(4-aminophenyl)amine (TAPA) with TFPA via conventional solvothermal condensation, generating MOF@COF core-shell hybrid material NH2-MIL-68@TPA-COF (Fig. 7). NH2-MIL68@TPA-COF displayed higher photocatalytic activity with the rate constant of $0.077 \mathrm{~min}^{-1}$, which was about 1.4 times higher than that of $\mathrm{NH}_{2}$-MIL-68, due to its large BET surface area as well as smaller band gap.

As discussed above, several strategies including functional building blocks incorporation, elemental doping, sensitizer, and hybrid construction have been utilized in enhancing photocatalytic performance COFs. Among them, while functional building blocks incorporation as the distinctive feature of COFs have been widely used, the exploration is far enough in view of the unlimited building molecules. And post-synthetic modification will also be a promising strategy to utilize photoactive groups which are difficult for ab initio construction. Besides, heterojunction constructing attracts considerable interest. By building suitable band positions, it is able to transfer photogenerated electron-hole pairs from the interface to the surface of two components, which leads to redox and reduction reactions. Indeed, new strategies with high performance are highly desired.

\section{Photocatalytic applications}

\subsection{Application in photocatalytic hydrogen evolution}

Nowadays, energy shortage is one of the most challenging issues, particularly in a clean and sustainable way. Hydrogen, as one of the most promising renewable energy sources, can be generated from water splitting under visible-light irradiation. ${ }^{172,173}$ COFs with diverse structural regularity, crystallinity and porosity are considered as promising photocatalytic hydrogen production platforms. ${ }^{174}$ Up to now, the highest photocatalytic hydrogen evolution rate of 19120 $\mu \mathrm{mol} \mathrm{h} \mathrm{h}^{-1} \mathrm{~g}^{-1}$ was reported by Tan and co-workers based on ter-CTF0.7, which was synthesized from 4,7-bis(4-formylphenyl)-2,1,3benzothiadiazole (M-BT), 3,6-dicarbaldehyde-N-ethylcarbazole (MCBZ), and terephthalimidamide dihydrochloride. ${ }^{175}$

The COF first used for photocatalytic hydrogen production was reported in 2014. ${ }^{39}$ The triazine-based building block was selected because of its high electron mobility and electron-withdrawing characteristic. ${ }^{176}$ Specifically, the crystalline hydrazone-linked COF (TFPT-COF) was prepared by condensation of 2,5-diethoxyterephthalohydrazide (DETH) with 1,3,5-tris-(4-formylphenyl)triazine (TFPT). Then, Pt as a proton reduction catalystand TFPT-COF as the photosensitizer was integrated to form TFPT-COF/ Pt photocatalyst for visible-light-induced hydrogen evolution with sodium ascorbate or TEOA as an electron donor. A hydrogen evolution rate of $1970 \mu \mathrm{mol} \mathrm{h}^{-1} \mathrm{~g}^{-1}$ was achieved with 10 vol\% TEOA, which was nearly 3 times higher than other outstanding photocatalytic systems including crystalline poly(triazine imide) and Pt-modified amorphous melon. ${ }^{40}$ Moreover, the quantum efficiency was determined to be $2.2 \%$ at $500 \mathrm{~nm}$. Interestingly, on the one hand, TFPT-COF with retained photoactivity lost its crystallinity after $92 \mathrm{~h}$ photocatalytic reaction, probably due to its exfoliation in the process; on the other hand, this filtered amorphous product could be easily reconverted to the crystalline TFPT-COF just by putting it under the original experiment conditions without additional new building units, which suggested that the connectivity and photoactivity of TFPT-COF was retained.

As discussed before, one of the most intriguing characters of COFs is structural tuneability, which allows for structure-to-function design at an atomic level. Indeed, many kinds of researches about COF-based photocatalysts for water splitting have been studies by tailoring the building blocks and linkages. For instance, a series of planar pyrene-based A-TEXPY-COFs was designed and synthesized by extending alkynes with the variation of phripheral heteromatic building units. ${ }^{177}$ The light-induced hydrogen evolution by COF photocatalyst was studied in the presence of a Pt co-catalyst by using 10 vol\% TEOA as a sacrificial electron donor. A-TEBPY-COF constructed from 1,3,6,8-tetrakis(4-ethynylbenzaldehyde)-pyrene (TEBPY) and hydrazine with the lowest nitrogen content and thereby 
the most advanced donor features, showed the highest $\mathrm{H}_{2}$ evolution rate of $98 \mu \mathrm{mol} \mathrm{h}^{-1} \mathrm{~g}^{-1}$ in this system. The results were in accordance with an increasing thermodynamic driving force for hydrogen reduction with decreasing nitrogen content.

Previous studies revealed that rigid, planar dibenzo[b, $d$ ] thiophene sulfone (DBTS) unit was conducive to visibleinduced photocatalytic evolution. ${ }^{178}$ The DBTS unit was incorporated into ordered COFs for the first time to investigate their photocatalytic activity. ${ }^{179}$ The as-prepared FS-COF exhibited a high hydrogen evolution rate, up to $16300 \mu \mathrm{mol} \mathrm{h}^{-1} \mathrm{~g}^{-1}$, which is almost ten times higher than $\mathrm{N}_{3}$-COF. Later, three Ketoenamine-based COFs were investigated to explore the effect of different groups on photocatalytic performance. ${ }^{180}$ Specifically, TpPa-COF-X (X $=-\mathrm{H}$, $\left(\mathrm{CH}_{3}\right)_{2}$, and $-\mathrm{NO}_{2}$ ) were constructed from the same host backbone with different functional groups anchored on the framework. In the photocatalytic experiment, $\mathrm{H}_{2}$ evolution efficiency decreased in the order of TpPa-COF- $\left(\mathrm{CH}_{3}\right)_{2}>\mathrm{TpPa}-\mathrm{COF}>\mathrm{TpPa}-\mathrm{COF}-\mathrm{NO}_{2}$. The order was attributed to the electron-donating ability of three groups, $-\mathrm{CH}_{3}>$ $-\mathrm{H}>-\mathrm{NO}_{2}$, which resulted in more efficient charge transferring within the COFs framework. Besides, Benzothiadiazole as the electron-withdrawing units and thiophene as the electron-donating moieties were selectively introduced into CTFs. ${ }^{181}$ The as-prepared CTF-BT/Th was dispersed in water containing 10 vol\% TEOA as a sacrificial agent and $3 \mathrm{wt} \% \mathrm{Pt}$ as a co-catalyst under the visible-light irradiation, exhibiting a maximum hydrogen evolution rate of 6600 $\mu \mathrm{mol} \mathrm{h} \mathrm{h}^{-1} \mathrm{~g}^{-1}$ and an AQE of $7.3 \%$ at $420 \mathrm{~nm}$. Notably, the AQE was the highest value as compared to the existed triazine-based polymer photocatalysts at that time. To further enhance the activity, attractive COF-based hybrid material was prepared based on benzoic acid-modified CTF-1 (B-CTF-1) and $\mathrm{NH}_{2}$-MIL-125(Ti) or $\mathrm{NH}_{2}$-UiO$66(\mathrm{Zr}) .{ }^{182}$ Photocatalytic results showed that the hydrogen production rate over $15 \mathrm{wt} \% \mathrm{NH}_{2}$-MIL-125(Ti)/B-CTF-1 (15TBC) was $360 \mu \mathrm{mol} \mathrm{h}^{-1} \mathrm{~g}^{-1}$ under visible light irradiation, which was more than twice as much as that of the B-CTF-1. The superior photocatalytic performance of the MOF/COF hybrids could be attributed to the formation of amide bonds between B-CTF-1 and MOFs, which facilitated the charge separation efficiency and improved the stability of the photocatalyst.

Notably, considering the charge recombination and the kinetic overpotential for hydrogen production, there is no evidence for current COFs to produce $\mathrm{H}_{2}$ without a co-catalyst. Metallic Pt with large work function has been widely used for electrons trapping among photocatalysis, which also provides efficient proton reduction sites, making the facile $\mathrm{H}_{2}$ formation. ${ }^{183}$ Thus, the COF backbone with $\mathrm{Pt}$ coordination sites enables the specific interaction of COF and Pt, leading to the enhanced charge transfer. However, the stablity of Pt in this environment limits its development. ${ }^{184,} 185$ Developing earthabundant, scalable, low-cost co-catalysts, which is water-soluble and can also interact with heterogeneous photoabsorber is urgent. Apart from $\mathrm{Pt}, \mathrm{MoS}_{2}$ quantum dots (QDs) with high quantum confinement and small-size effect also acted as an excellent candidate as the hydrogen evolution co-catalyst. ${ }^{186,}{ }^{187} \mathrm{MoS}_{2}$ quantum dots (QDs) modified CTFs ( $\mathrm{MoS}_{2} / \mathrm{CTFs}$ ) composites for enhanced photocatalytic hydrogen production from water under visible-light irradiation were reported. $\mathrm{MoS}_{2}$ QDs were uniformly distributed on the CTFs surface by an in situ photo-deposition method. ${ }^{188}$ The as-synthesized $\mathrm{MoS}_{2} / \mathrm{CTFs}$ composites distinctly enhanced the photocatalytic hydrogen production over original CTFs and $\mathrm{MoS}_{2} / \mathrm{g}-\mathrm{C}_{3} \mathrm{~N}_{4}$ composite. The nature of this high activity was attributed to the interactions between $\mathrm{MoS}_{2}$ and CTFs, which resulted in the fast and efficient transfer and separation of the electrons and holes in the composites. Cobaloximes, as the most efficient transition metal-based co-catalyst, features easy synthesis, low overpotentials for hydrogen evolution, and can be easily introduced into the photocatalytic system. ${ }^{189}$ Lotsch and co-workers firstly selected noble-metal-free cobaloximes as a co-catalyst in the $\mathrm{N}_{2}$-COF-based photocatalytic proton reduction. ${ }^{190}$ Several factors influenced the $\mathrm{H}_{2}$ evolution rate including the solvent, sacrificial donor, reaction $\mathrm{pH}$, and the fundamental properties of COFs such as crystalline and porosity. By selecting azine-linked $\mathrm{N}_{2}$-COF as the photosensitizer, chloro(pyridine)cobaloxime as the co-catalyst, and TEOA as a sacrificial donor, $\mathrm{H}_{2}$ evolution rate of $782 \mu \mathrm{mol} \mathrm{h}^{-1} \mathrm{~g}^{-1}$ and TON of 54.4 were obtained in a mixture of water and acetonitrile. Herein electrons were transformed form the LUMO of COF to the co-catalyst, following a monometallic pathway of $\mathrm{H}_{2}$ evolution from the CollIhydride and/or Co"l-hydride species. As cobaloxime tends to be inactive within few hours owing to decomposition or hydrogenation, an earth-abundant, noble-metal-free nickelthiolate hexameric cluster was further employed. ${ }^{191}$ A visible-light-induced hydrogen evolution system was constructed with TzDTz-linked COF (TpDTz: Tp and 4,4'-(thiazolo[5,4-d]thiazole-2,5-diyl)dianiline) as a photosensitizer, Ni-thiolate cluster (NiME) as a co-catalyst, and TEOA as a sacrificial agent. As a result, sustained high $\mathrm{H}_{2}$ evolution rate of $941 \mu \mathrm{mol} \mathrm{h}{ }^{-1} \mathrm{~g}^{-1}$ and a TON $\mathrm{Ni}_{\mathrm{i}}>103$ were observed over $70 \mathrm{~h}$ visiblelight illumination.

\subsection{Application in photocatalytic oxygen evolution}

Water oxidation for oxygen evolution is the rate-determining step in overall water splitting and is more complex due to the four-electron redox process. ${ }^{192}$ Recently, photocatalytic water oxidation was examined by COF photocatalysts, although the studies are far less than that for photocatalytic hydrogen evolution. ${ }^{193,194}$ For example, CTF-1 was synthesized via microwave-assisted condensation at different powers, and then was applied to water splitting. ${ }^{76}$ The oxygen evolution from the water was performed by using $\mathrm{AgNO}_{3}$ as a sacrificial electron acceptor and $\mathrm{RuO}_{\chi}$ as a co-catalyst. With the visible light irradiation, the highest oxygen production rate of $c a .140$ $\mu \mathrm{mol} \mathrm{h}{ }^{-1} \mathrm{~g}^{-1}$ was achieved by $3 \mathrm{wt} \%$ RuOx/CTF-1-100W. Notably, the photocatalytic activity of CTF-1-100W without a co-catalyst was even 3 times higher than that of $g-\mathrm{C}_{3} \mathrm{~N}_{4}$ with $\mathrm{RuO}_{\chi}$ co-catalyst and 20 times better when CTF-1-100W when decorated a $\mathrm{RuO}_{\chi}$ cocatalyst. The AQE for oxygen production was further determined to be $c a .3 .8 \%$ at $420 \mathrm{~nm}$. These results suggested the considerable potential of CTFs for photocatalytic oxygen evolution under visiblelight irradiation. Meanwhile, $2.01 \mathrm{wt} \% \mathrm{Pt} / \mathrm{CTF}-1-100 \mathrm{~W}$ showed a high hydrogen evolution of $5500 \mu \mathrm{mol} \mathrm{h}^{-1} \mathrm{~g}^{-1}$ with TEOA as a sacrificial electron donor and $\mathrm{Pt}$ as a co-catalyst under visible-light irradiation ( $\lambda \geq 420 \mathrm{~nm}$ ). CTF-0 based on 1,3,5-tricyanobenzene possessed the highest nitrogen to carbon ratio with alternative 
benzene and triazine units, which provided more active sites for oxidation reactions. Microwave-assisted synthesis and ionothermal synthesis were also used to produce CTF-O-M and CTF-0-I, respectively. ${ }^{195}$ The results suggested that the sample synthesized via ionothermal synthesis (e.g. CTF-0-I) showed a higher oxygen evolution. Under full arc and visible-light irradiation, CTF-0-I exhibited the oxygen generation of 226 and $59 \mu \mathrm{mol} \mathrm{g}^{-1}$ in the first hour, respectively, in the presence of $\mathrm{Ag}^{+}$ as the electron scavenger.

\subsection{Application in the reduction of carbon dioxide}

With the fast-growing population and global economy, the increasing fossil fuel consumption leads to the excess emission of carbon dioxide $\left(\mathrm{CO}_{2}\right)$, which causes serious environmental problems like the greenhouse effect. ${ }^{196}$ Many solutions such as amines and ionic liquids adsorption, oxy-fuel combustion, and carbonate looping have been put forward pertaining to this dilemma. In recent years, photocatalytic reduction of $\mathrm{CO}_{2}$ to clean hydrocarbon fuels as an attractive strategy to address the environment and energy issues at the same time has aroused great interest. COFs, the promising photocatalytic candidates, with their high $\mathrm{CO}_{2}$ adsorption capacity and selectivity, are recognised as a dramatic platform for photocatalytic reduction of $\mathrm{CO}_{2}$.

Azine-based COFs with the existence of $\pi$-stacking aromatic units has been regarded as one of the most attractive candidates for photocatalysis. A large conjugated structure could facilitate the separation and transfer of photo-induced electrons/holes. Recently, two azine-linked crystalline COFs ACOF-1 (hydrazine, TFB) and $\mathrm{N}_{3}-\mathrm{COF}$ were utilized as photocatalysts for visible-light-induced reduction of $\mathrm{CO}_{2}$ with $\mathrm{H}_{2} \mathrm{O}$ as a hole scavenger. Understandably, in the reaction of $\mathrm{CO}_{2}$ photoreduction, the $\mathrm{CO}_{2}$ adsorption capability of the catalyst is an important prerequisite. In this study, the high surface area of ACOF-1 (1053 $\left.\mathrm{m}^{2} \mathrm{~g}^{-1}\right)$ and $\mathrm{N}_{3}$-COF $\left(1412 \mathrm{~m}^{2} \mathrm{~g}^{-1}\right)$ with abundantly accessible nitrogen sites rendered them with high $\mathrm{CO}_{2}$ adsorption, leading to the facilitated photocatalytic reduction of $\mathrm{CO}_{2}$ to $\mathrm{CH}_{3} \mathrm{OH}$. Upon $24 \mathrm{~h}$ visible light irradiation, the total amounts of $\mathrm{CH}_{3} \mathrm{OH}$ generated over $\mathrm{N}_{3}$-COF was $13.7 \mu \mathrm{mol} \mathrm{g}{ }^{-1}$, which was much higher than that of ACOF-1 $\left(8.6 \mu \mathrm{mol} \mathrm{g}^{-1}\right)$. Compared with ACOF-1, $\mathrm{N}_{3}$-COF with electron-poor triazine moieties was able to stabilize the negative charge generated on COF which was important for the enhanced photocatalytic activity. It should be noted that the activity of these COFs outperformed other materials such as $\mathrm{g}-\mathrm{C}_{3} \mathrm{~N}_{4}(4.8 \mu \mathrm{mol}$ $\left.\mathrm{g}^{-1}\right)$ under similar reaction conditions. ${ }^{197,} 198$ Furthermore, the electronic properties and configuration of $\mathrm{N}_{3}-\mathrm{COF}$ and ACOF-1 were calculated with density functional theory (DFT). The results suggested that the potential of their LUMO was enough to drive $\mathrm{CO}_{2}$ reduction although the band gap was not suitable for the visible light response. Under visible light irradiation, the excited electrons at the LUMO energy level could reduce the adsorbed $\mathrm{CO}_{2}$ on the catalyst surface to produce methanol.

Apart from using a COF itself as a photocatalyst for the reduction of $\mathrm{CO}_{2}$, crystalline COFs have also been considered as a photosensitive supporter to stabilize metallic active moieties for $\mathrm{CO}_{2}$ conversion. Rhenium(I) bipyridine (bpy) complexes are widely used in constructing photocatalyst to selectively reduce $\mathrm{CO}_{2}$ into $\mathrm{CO}$ under visible light irradiation. A pyridine-based CTF, namely CTF-py, constructed from 2,6-dicyanopyridine (DCP) with abundant $\mathrm{N}, \mathrm{N}$ chelating sites allowed for coordination of rhenium complexes targeting for $\mathrm{CO}_{2}$ photoreduction. A CTF-py was firstly synthesized via traditional trimerization reaction, and then rhenium complex $\mathrm{Re}(\mathrm{CO})_{5} \mathrm{Cl}$ was introduced into the nitrogen sites of CTF-py to obtain Re-CTF-py through the post-synthetic modification. ${ }^{199}$ The photocatalytic $\mathrm{CO}_{2}$ conversion was investigated in a solid-gas system under the irradiation of UV-Vis light, which could avoid dimerization and leaching of reactive species. The production of CO linearly increased with the irradiation time. The highest $\mathrm{CO}$ production rate of $353.05 \mu \mathrm{mol} \mathrm{g}{ }^{-1} \mathrm{~h}^{-1}$ was observed on Re-CTF-py after $10 \mathrm{~h}$ continuous irradiation, while that of pristine CTF-py and the physical mixture were only $13.4 \mu \mathrm{mol} \mathrm{g} \mathrm{g}^{-1} \mathrm{~h}^{-1}$ and $156.2 \mu \mathrm{mol} \mathrm{g}^{-1} \mathrm{~h}^{-1}$, respectively. The photogenerated electrons could easily transfer from CTF-py to Re via the coordination bond, indicating the efficient separation of photo-induced carriers. Using a similar strategy, a triazine COF derived from the condensation of TTA and 2,2-bipyridyl5,5-dialdehyde (BPDA) was selected as a photosensitizer to incorporate with $\operatorname{Re}$ complex $\left(\operatorname{Re}(\mathrm{bpy})(\mathrm{CO})_{3} \mathrm{Cl}\right)$ for photocatalytic conversion of $\mathrm{CO}_{2}$ to $\mathrm{CO}$. By using Xe lamp as a light source $(\lambda \geq 420$ $\mathrm{nm}$ ) and TEOA as an electron donor, the resulting Re-COF showed a steadily $\mathrm{CO}$ generation of $15 \mathrm{mmol} / \mathrm{g}$ for more than $20 \mathrm{~h}$ after $15 \mathrm{~min}$ induction period with a TON of 48 , which was 22 times better than its homogeneous $\operatorname{Re}\left(\right.$ bpy) $(\mathrm{CO}){ }_{3} \mathrm{Cl}$.

Very recently, COFs were also developed as functional supporters, like TpBpy COF, to anchor active sites for photocatalytic $\mathrm{CO}_{2}$ conversion. Compared with TpBpy, the introduction of $\mathrm{Ni}$ resulted in a red-shifted absorption edge and narrower band gap due to the increased delocalization. Moreover, Ni-TpBpy helped to enhance the $\mathrm{CO}_{2}$ adsorption capacity and isosteric heats, which could be ascribed to the Lewis acid-base interaction between adsorbed $\mathrm{CO}_{2}$ molecules and loaded $\mathrm{Ni}$ ions. In the experiment of $\mathrm{Ni}$-TpBpy photocatalytic $\mathrm{CO}_{2}$ reduction, $[\mathrm{Ru}(\mathrm{bpy})]_{3} \mathrm{Cl}$ acted as a photosensitizer and TEOA served as an electron donor. Upon illumination, $\mathrm{Ru}(\mathrm{bpy})_{3}{ }^{2+}$ was excited and transferred electrons to reduce the coordinated $\mathrm{CO}_{2}$ molecules on Ni-TpBpy. The affinity of $\mathrm{CO}_{2}$ on $\mathrm{Ni}$ sites over $\mathrm{H}^{+}$was crucial for the inhibition of $\mathrm{H}_{2}$ formation. As a result, the generated amount of $\mathrm{H}_{2}$ and $\mathrm{CO}$ from Ni-TpBpy catalytic system were 170 and $4057 \mu \mathrm{mol} \mathrm{g}^{-1}$ within 5 hours, respectively, indicating a higher selectivity to $\mathrm{CO}$. This $\mathrm{CO}$ production was comparable to other previous reported MOFs and COFs. Control experiments revealed that single Ni sites in TpBpy framework acted as catalytic sites while TpBpy facilitated the activity as well as selectivity as a functional support.

\subsection{Application in the degradation of pollutants}

The unscrupulous discharge of raw sewage into environment has led to a huge threat to ecological systems and human health. Organic pollutant, such as dyes, antibiotics and fertilizers, was one of the most persistent components to be degraded. Among various technologies 205,236 , photocatalysis utilizing the most abundant solar energy is recognized to be an environmental, sustainable and effective technology for the decomposition of organic contaminants to non-hazardous products. 2, 200, 201 Various kinds of photocatalysts 
such as $\mathrm{TiO}_{2},{ }^{202,} 203 \mathrm{CdS},{ }^{9,}, 204 \mathrm{BiOCl},{ }^{205,} 206$ and g- $\mathrm{C}_{3} \mathrm{~N}_{4}{ }^{12,} 207$ have been extensively studied. However, the limited structural and functional tunability hinders their development. For example, g- $\mathrm{C}_{3} \mathrm{~N}_{4}$ based on triazine or heptazine units offers limited chemical variety and is hard for systematic post-modification. In this regard, COFs with remarkable structural regularity were supposed to be an intriguing platform for photocatalytic degradation of pollutants such as RhB, methyl blue (MB), methyl orange (MO), tetracycline (TC).

Considering the similar features of nitrogen-rich rings and $\pi$ conjugated structure to g- $\mathrm{C}_{3} \mathrm{~N}_{4}$, COFs with visible-light catalytic active moiety $\mathrm{C}_{3} \mathrm{~N}_{4}$ exhibited great potential to become a qualified photocatalyst. Over the years, triazine-based COFs have been explored to perform superior photodegradation efficiency, compared with g- $\mathrm{C}_{3} \mathrm{~N}_{4}{ }^{208-210}$ Likewise, ultrastable TpMA with $\mathrm{C}_{3} \mathrm{~N}_{4}$ active center was prepared by the co-condensation of MA and Tp under solvothermal condition, which involved a two-step path of reversible Schiff-base reaction and irreversible enol-keto tautomerization. This subtly designed structure endowed TpMA with the enhanced light-harvesting capability and photooxidation property as a result of the reduced band gap and positive-shifted VB position. MO was selected as a model pollutant to assess the photocatalytic performance of the as-prepared TpMA under visiblelight illumination. MO molecules could be degraded with TPMA photocatalyst within $40 \mathrm{~min}$, whereas the bulk g- $\mathrm{C}_{3} \mathrm{~N}_{4}$ photocatalytic system found almost no degradation under the same conditions. In order to exclude the photosensitive effect, colorless organic contaminant phenol was also chosen to evaluate the photocatalytic performance of TpMA. Notably, $90 \%$ of phenol was decomposed by TpMA online comparison with $8 \%$ decomposition by g- $\mathrm{C}_{3} \mathrm{~N}_{4}$ after 40 min irradiation. Upon visible light irradiation, TpMA could be excited when the energy was greater than or equal to its band gap $(2.30 \mathrm{eV})$. Then the dissolved $\mathrm{O}_{2}$ quickly captured the electrons from $\mathrm{CB}$ to obtain $\mathrm{O}_{2} \cdot\left(\mathrm{E}^{0}, \mathrm{O}_{2} / \mathrm{O}_{2} \cdot=-0.33 \mathrm{eV}\right.$ vs. $\left.\mathrm{NHE}\right)$, and the obtained $\mathrm{O}_{2}$ radicals reacted with $\mathrm{H}_{2} \mathrm{O}$ to further produce active $\mathrm{OH}$. Consequently, MO molecules could be effectively oxidized and mineralized by reactive oxygen species $\mathrm{O}_{2}{ }^{-}$and $\mathrm{OH}^{-}$. According to the total organic carbon (TOC) measurements, TpMA achieved $36.7 \%$ of MO mineralization after a 40 min-irradiation.

Recently, three imine-linked COFs with visible-light catalytic active triazine ring were prepared by condensation of three different nitrogen-contained building blocks with the same aldehyde $A 4,4^{\prime}, 4^{\prime \prime}$ (1,3,5-triazine-2,4,6-triyl)tribenzaldehyde, which yielded $\operatorname{COF}_{A+B}$, $\mathrm{COF}_{\mathrm{A}+\mathrm{C}}, \mathrm{COF}_{\mathrm{A}+\mathrm{D}}$, separately. Specifically, three different monomers were 1,3,5-tris(4-aminophenyl)benzene (B), 4,4',4')-(1,3,5-triazine2,4,6-triyl)trianiline (C), and 2,4,6-tris(4-hydrazinylphenyl)-1,3,5triazine (D). Colorless phenol and MO dye were selected as model pollutants to evaluate the photocatalytic performance of the asprepared COFs. The BET surface area and the corresponding pore volume followed the similar trend as $\mathrm{COF}_{\mathrm{A}+\mathrm{D}}\left(458 \mathrm{~m}^{2} \mathrm{~g}^{-1}, 0.434 \mathrm{~cm}^{3} \mathrm{~g}\right.$ 1) < $\operatorname{COF}_{A+B}\left(907 \mathrm{~m}^{2} \mathrm{~g}^{-1}, 0.436 \mathrm{~cm}^{3} \mathrm{~g}^{-1}\right)<\operatorname{COF}_{\mathrm{A}+\mathrm{C}}\left(1903 \mathrm{~m}^{2} \mathrm{~g}^{-1}, 0.455\right.$ $\left.\mathrm{cm}^{3} \mathrm{~g}^{-1}\right)$. Although the large surface area and accessible porous nature are beneficial to mass transfer, ${ }^{114,211}$ the interaction between adsorbent-adsorbate should be taken into high priority, especially in the liquid phase. In the case of $\mathrm{COF}_{A+D}$, it exhibited higher adsorption activity than the other two COFs due to the existence of $\mathrm{H}$-bonding between azo groups of $\mathrm{MO}$ and hydrazine groups of $\mathrm{COF}_{\mathrm{A}+\mathrm{D}}$. $\mathrm{A}$ similar phenomenon was also observed with phenol since the $\mathrm{N}$-containing group could interact with the hydroxyl groups of phenol. Therefore, the adsorption of $\mathrm{MO}$ and phenol followed the reverse trend as the BET surface area, as $\mathrm{COF}_{\mathrm{A}+\mathrm{B}}>\mathrm{COF}_{\mathrm{A}+\mathrm{D}}>\mathrm{COF}_{\mathrm{A}+\mathrm{C}}$. MO molecules could be completely degraded by $\mathrm{COF}_{\mathrm{A}+\mathrm{C}}$ under $30 \mathrm{~min}$ visible light irradiation, while only $29.6 \% \mathrm{MO}$ could be removed by $\mathrm{COF}_{\mathrm{A}+\mathrm{B}}$, and COFA+D observed almost no degradation. Similarly, the photocatalytic degradation of phenol followed the order of $\mathrm{COF}_{\mathrm{A}+\mathrm{C}}>$ $\mathrm{COF}_{\mathrm{A}+\mathrm{B}}>\mathrm{COF}_{\mathrm{A}+\mathrm{D}}$. The hydrazine groups on $\mathrm{COF}_{\mathrm{A}+\mathrm{D}}$ broke the $\pi$ delocalized electron system, leading to the reduction of electrontransfer conductivity and decrease the interfacial charge transfer; and the $\mathrm{CB}$ edge potential of $\mathrm{COF}_{\mathrm{A}+\mathrm{D}}$ was too positive to reduce the molecular oxygen to $\mathrm{O}_{2}{ }^{-}$species, resulting in the poor photocatalytic performance. On the other hand, different from $\mathrm{COF}_{\mathrm{A}+\mathrm{B}}$, the interdigitated triazine-benzene heterojunctions in $\mathrm{COF}_{\mathrm{A}+\mathrm{C}}$ enabled the decreased electron-hole recombination. As a result, $\mathrm{COF}_{\mathrm{A}+\mathrm{C}}$ with a higher density of active centres and conjugation degrees showed the highest photocatalytic performance. When $\mathrm{COF}_{\mathrm{A}+\mathrm{C}}$ was excited with photons of energy exceeding (or equal to) the band gap, photoinduced electrons were injected into the $C B$. Subsequently, the accumulated electrons in the $\mathrm{CB}$ were trapped by the dissolved $\mathrm{O}_{2}$ to yield abundant $\mathrm{O}_{2}{ }^{-}$, which could further react with $\mathrm{H}_{2} \mathrm{O}$ to eventually form $\mathrm{OH} \bullet$; while holes can easily spread out over polymer system to oxidized pollutants or water, resulting in the effective spatial charge separation. These finally formed reactive oxygen species $\left(\mathrm{O}_{2}{ }^{-}\right.$and $\mathrm{OH} \cdot$ radicals) could efficiently degrade the organic pollutants. In addition, $\mathrm{COF}_{\mathrm{A}+\mathrm{C}}$ did not show any major loss of the activity after four photocatalytic cycles, indicating its high stability and renewability.

Besides, other functional building blocks have also been utilized to construct COFs with high photocatalytic performance. For example, heptazine unit was embedded into the framework of CTF (forming PCN-1 and PCN-2), which was demonstrated to possess high photocatalytic performance toward degradation of RhB. ${ }^{212}$ In detail, PCN-1 was prepared by the polymerization of melem and 2,4,6Triformylphloroglucinol by using a solvent of dimethyl sulfoxide, whereas $\mathrm{PCN}-2$ with crystalline structure was obtained by incorporating melem moieties into CTF. Compared with the traditional polymer semiconductor $\mathrm{g}_{-} \mathrm{C}_{3} \mathrm{~N}_{4}$, the $\mathrm{PCN}$ polymers showed broader absorption wavelength, even extended to the entire visible region. Moreover, the enhanced specific BET surface area of $\mathrm{PCN}-2$ ensured for more active surface sites, thereby giving more chance for reactants to access for photoredox reactions. As for the photocatalytic performance, PCN-1 and CTF could degrade RhB within $120 \mathrm{~min}$ and $60 \mathrm{~min}$, respectively, while PCN-2 could degrade RhB within 25 min under visible light irradiation. Triptycene with 3D spatial orientation containing three benzene rings is another attractive conjugated building unit for microporous materials synthesis. A Triptycene-Based imine-linked covalent organic polymer (TP-COP) was prepared for organic dye degradation. Graphene-like layered TP-COP was obtained by manual grinding of terepthaldehyde and triaminotriptycene at room-temperature. The solid-state diffuse reflectance spectrum (DRS) indicated that TP-COF responded to 
visible light, and a narrow band gap of $~ 2.49 \mathrm{eV}$ was determined by the Tauc's plot. 95\% of RhB degradation efficiency could be achieved within $160 \mathrm{~min}$ under sunlight irradiation. Meanwhile, TP-COP possessed excellent reusability in RhB degradation without any visible performance decay.

In addition to the building blocks design, morphology control has also been regarded as an essential method to optimize catalytic efficiency of photocatalysts. ${ }^{55,213,214}$ Hollow architectures have been investigated to not only promote the interaction between catalysts and substrates by decreasing thickness of structure but also enhance light absorption by multiple light reflections. ${ }^{151}$ As for other morphologies, TpMA with thread-like morphology could be synthesized by ball milling varied with the adding amounts of liquid during the process. With the addition of p-toluenesulfonic acid (PTSA) and $1 \mathrm{~mL}$ solvents, crystalline TpMA $\mathrm{A}_{(1 \mathrm{~mL})}$ was achieved with the welldefined morphology of interwoven thread shape. When the solvent volume was increased to $3 \mathrm{~mL}$, crystalline $\operatorname{TpMA}_{c(3 \mathrm{~mL})}$ with thin ribbon-like morphology was presented. Both $\left.\operatorname{TpMA}_{c(3} \mathrm{mL}\right)$ and $\operatorname{TpMA}_{\mathrm{C}(1 \mathrm{~mL})}$ were able to respond to visible light and the optical band gap of $\operatorname{TpMA}_{C(3 \mathrm{~mL})}$ and $\left.T p M A_{C(1} \mathrm{mL}\right)$ was determined to be $2.29 \mathrm{eV}$ and $2.56 \mathrm{eV}$, respectively. $10 \mathrm{mg} \mathrm{L}^{-1}$ phenol was chosen as a model environmental contaminant to evaluate the photocatalytic

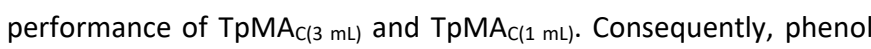
was completely decomposed after $60 \mathrm{~min}$ over $\operatorname{TpMA}_{\mathrm{C}(3 \mathrm{~mL})}$ under visible light irradiation, while only $83.5 \%$ phenol was degraded by

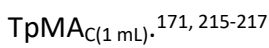

Except for the morphology control, heterojunction construction has also been used to improve the photocatalytic degradation performance of COFs. For example, a Z-scheme MOF/COF heterojunction was firstly reported by the incorporation of $\mathrm{NH}_{2}$-MIL125(Ti) with TTB-TTA (TTA: 4,4', $4^{\prime \prime}$-(1,3,5-triazine-2,4,6triyl)trianiline, $\quad$ TTB: $\quad 4,4^{\prime}, 4^{\prime \prime}$-(1,3,5-triazine-2,4,6triyl)tribenzaldehyde). ${ }^{217}$ The $\mathrm{NH}_{2}$-MIL-125(Ti)/TTB-TTA hybrid material exhibited enhanced photocatalytic performance for $\mathrm{MO}$ degradation because of efficient charge separation through the covalent heterojunction interface. In addition, BiOBr/CTF-3D composite was designed and prepared, showing enhanced photocatalytic activity toward antibiotic removal.

\section{Conclusions and outlook}

COFs, as a kind of newly developing crystalline porous materials, are built from organic building units with covalent linkers via reticular chemistry, leading to the features of high porosity, large surface area, and low density. More excitingly, versatile organic building blocks and various covalent bonds for COF synthesis render them with fascinating tailored functionalities. In this regard, COFs possess great potential in diverse applications including photocatalysis. Compared to other conventional heterogeneous photocatalysis, the COFs display some inherent advantages including: (i) COFs with predesignable structures are capable of optimizing photocatalytic performance by deliberately selecting functional building blocks for de novo synthesis, or incorporating functional groups by post-synthesis modification; (ii) the inherent porosity and large surface area of COFs can facilitate the charge diffusion to the surface, and also render them with enhanced accessible surface; (iii) the controllable crystalline nature without unnecessary defects, which are usually considered as the electron-hole recombination centres, greatly suppresses their volume recombination; and (iv) the high stability stem from covalent linkages leads to improved recyclability, and the photoactive building molecules covalently linked in COF backbone could prolong the excited state lifetimes by avoiding collisions. In this review, recent progress and advances relating to the COFs design and their photocatalytic application were presented. A growing number of covalent linkages amenable to structure and property design was briefly summarized, and controllable morphologies including OD structures, 1D structures, 2D structures as well as 3D structures were described. Moreover, strategies for enhancing the photocatalytic activity of COF materials were discussed. In addition, the main applications of COFs as photocatalysts regarding photocatalytic $\mathrm{H}_{2}$ evolution, $\mathrm{CO}_{2}$ reduction and photo-degradation of pollutants were presented. While some intriguing progress, the study of COFs and COF-based photocatalysts is still at its infancy stage and several issues should be solved for future development.

1. The structures, morphologies and properties of COFs are most likely to be changed with different synthesis methods and reaction conditions, thereby leading to the different photocatalytic performance of COFs. Synthetic strategies such as solvothermal synthesis, ${ }^{30,} 218$ ionothermal synthesis, ${ }^{219,} 220$ microwave synthesis $76,195,221,222$ and room temperature synthesis ${ }^{223,} 224$ have been developed for COFs synthesis. While solvothermal synthesis is the most widely used method, the harsh synthesis conditions such as long reaction time, high temperature and pressure, making it difficult for large-scale production. lonothermal synthesis here is utilized for the synthesis of photoactive triazine core, but the high reaction temperature and low crystalline products hamper the development. The microwave-assisted method and room temperature reaction seem to be better choices. However, only a few examples were reported, ${ }^{76}, 195,221-223$ thus further improvement is needed. Hence, operative, low cost but effective synthetic methods with mild reaction conditions are eager to be introduced for the development of COFs with enhanced photocatalytic activity.

2. Despite some successful examples for COF-based photocatalysts, the construction of COFs as photocatalysts is far from enough. The study of COF-based photocatalysts just started and every aspects of photocatalytic performance need be strengthened. For example, limited photocatalytic-related functional groups have been employed, and solid-state properties including porosity, crystallinity and photostability should be optimized. In addition, more attention should be paid to the investigation of morphology and defect engineering. Notably, for the design of COF-based photocatalysts, basic characteristics including efficient light-harvesting especially for visible light absorption, effective photogenerated electron-hole separation, and high charge transfer mobility need to be considered. Owing to the pre-designable feature of COFs, it 
would be of great interest to explore new COFs with functionalized building blocks for the special use of photocatalytic reactions. Meanwhile, post-synthetic modification can also be used to introduce specific functional groups into the COF backbone. For example, as learnt from other traditional photocatalysts, long-wavelength-lightresponsive building blocks such as lanthanide-based molecules and phthalocyanine units could be incorporated into COFs to extend the light absorption from visible light to NIR light. Photoactive metal ions are suggested to be introduced as cocatalysts for effective charge separation. Constructing COFs with a two-dimensional and $\pi$-coordination structure would be beneficial for charge transfer. Moreover, incorporating COFs into semiconductors represents a promising strategy aiming to reduce the electron-hole recombination. ${ }^{225}, 226$

3. The fundamental mechanism of the COF-based photocatalytic system, especially the structure-activity relationship, still remains unclear. Theoretical calculation as a very useful tool is capable of predicting the structures and properties as well as simulating the photocatalytic process. For example, by the utilization of first-principle calculation, three 2D-CTF models CTF-0, 65 CTF- 1 , and CTF-2 were investigated including electronic band structures, conduction band minimum (CBM)/ valence band maximum (VBM) position, work functions, and optical absorption spectra. As a result, 2D-CTFs with controllable construction are better candidates for visiblelight-induced water splitting, which stimulated the experimental research for their photocatalytic properties. Besides, advance characterizations, especially in-situ and even operando technologies should be taken into consideration to reveal the mechanism behind all the photocatalytic processes, which would provide the insight for further development of efficient COFs-based photocatalysts. Technologies such as insitu FT-IR, in- situ X-ray absorption spectroscopy (XPS) and insitu extended $X$-ray absorption fine structure (EXAFS) are highly recommended to monitor the reaction process, distinguishing reactive intermediates and investigating the active sites. More specifically, spectroscopy technologies, such as photoluminescence ( $\mathrm{PL}$ ) spectroscopy, transient absorption (TA) spectroscopy and Kelvin probe force microscopy-based spatially resolved surface photovoltage technique are also needed for the optical and electronic properties analysis, corresponding to charge carrier transfer and recombination.

\section{Conflicts of interest}

There are no conflicts to declare.

\section{Acknowledgements}

This work was supported by the National Natural Science Foundation of China (No. 51521006, 51709101, 51508177, 51579098, 51579096, 51779090), the National Program for Support of Top-Notch Young Professionals of China (2012, 2014), Hunan Provincial Science and Technology Plan Project (No.2016RS3026, 2017SK2243, 2017SK2241), the Program for
Changjiang Scholars and Innovative Research Team in University (IRT-13R17) and the Three Gorges Follow-up Research Project (2017HXXY-05). W. H, L. X. Y and T. J. W are thankful for the financial support from UK EPSRC (EP/N009533/1), Royal Society-Newton Advanced Fellowship grant (NA170422) and the Leverhulme Trust (RPG-2017-122).

\section{Notes and references}

1. R. Fouquet, Nat Energy, 2016, 1, 16098.

2. C. Y. Zhou, C. Lai, C. Zhang, G. M. Zeng, D. L. Huang, M. Cheng, L. Hu, W. P. Xiong, M. Chen, J. J. Wang, Y. Yang and L. B. Jiang, Appl Catal B-Environ, 2018, 238, 6-18.

3. K. He, G. Q. Chen, G. M. Zeng, A. W. Chen, Z. Z. Huang, J. B. Shi, T. T. Huang, M. Peng and L. Hu, Appl Catal B-Environ, 2018, 228, 19-28.

4. F. A., K. Honda, Nature, 1972, 238, 37-38.

5. J. H. Carey, J. Lawrence and H. M. Tosine, Bull. Environ. Contam. Toxicol., 1976, 16, 697-701.

6. W. Li, A. Elzatahry, D. Aldhayan and D. Y. Zhao, Chemical Society reviews, 2018, 47, 8203-8237.

7. J. Schneider, M. Matsuoka, M. Takeuchi, J. L. Zhang, Y. Horiuchi, M. Anpo and D. W. Bahnemann, Chemical reviews, 2014, 114, 9919-9986.

8. O. Ola and M. M. Maroto-Valer, J Photoch Photobio C, 2015, 24, 16-42.

9. Q. Li, X. Li, S. Wageh, A. A. Al-Ghamdi and J. G. Yu, Adv Energy Mater, 2015, 5, 1500010.

10. J. X. Low, B. Z. Dai, T. Tong, C. J. Jiang and J. G. Yu, Advanced materials, 2019, 31, 1802981.

11. L. Cheng, Q. J. Xiang, Y. L. Liao and H. W. Zhang, Energy \& Environmental Science, 2018, 11, 1362-1391.

12. J. W. Fu, J. G. Yu, C. J. Jiang and B. Cheng, Adv Energy Mater, 2018, 8, 1701503.

13. W. J. Ong, L. L. Tan, Y. H. Ng, S. T. Yong and S. P. Chai, Chemical reviews, 2016, 116, 7159-7329.

14. S. W. Cao and J. G. Yu, Journal of Physical Chemistry Letters, 2014, 5, 2101-2107.

15. D. N. Jiang, P. Xu, H. Wang, G. M. Zeng, D. L. Huang, M. Chen, C. Lai, C. Zhang, J. Wan and W. J. Xue, Coordination Chemistry Reviews, 2018, 376, 449-466.

16. A. Dhakshinamoorthy, A. M. Asiri and H. Garcia, Angew Chem Int Edit, 2016, 55, 5414-5445.

17. M. D. Hernandez-Alonso, F. Fresno, S. Suarez and J. M. Coronado, Energy \& Environmental Science, 2009, 2, 12311257.

18. G. P. Dong, Y. H. Zhang, Q. W. Pan and J. R. Qiu, J Photoch Photobio C, 2014, 20, 33-50.

19. Y. O. Wang, A. Vogel, M. Sachs, R. S. Sprick, L. Wilbraham, S. J. A. Moniz, R. Godin, M. A. Zwijnenburg, J. R. Durrant, A. I. Cooper and J. W. Tang, Nat Energy, 2019, 4, 746-760.

20. T. Banerjee, K. Gottschling, G. Savasci, C. Ochsenfeld and B. V. Lotsch, Acs Energy Lett, 2018, 3, 400-409.

21. X. Chen, M. Addicoat, E. Q. Jin, L. P. Zhai, H. Xu, N. Huang, Z. Q. Guo, L. L. Liu, S. Irle and D. L. Jiang, J Am Chem Soc, 2015, 137, 3241-3247.

22. G. Q. Lin, H. M. Ding, R. F. Chen, Z. K. Peng, B. S. Wang and C. Wang, J Am Chem Soc, 2017, 139, 8705-8709.

23. X. S. Ding, J. Guo, X. A. Feng, Y. Honsho, J. D. Guo, S. Seki, P. Maitarad, A. Saeki, S. Nagase and D. L. Jiang, Angew Chem Int Edit, 2011, 50, 1289-1293. 
24.

A. P. Cote, A. I. Benin, N. W. Ockwig, M. O'Keeffe, A. J. Matzger and O. M. Yaghi, Science, 2005, 310, 1166-1170.

25. S. J. Lyle, P. J. Waller and O. M. Yaghi, Trends in Chemistry, 2019, 1, 172-184.

26. H. Lyu, C. S. Diercks, C. H. Zhu and O. M. Yaghi, J Am Chem Soc, 2019, 141, 6848-6852.

27. S. C. Yan, X. Y. Guan, H. Li, D. H. Li, M. Xue, Y. S. Yan, V. Valtchev, S. L. Qiu and Q. R. Fang, J Am Chem Soc, 2019, 141, 2920-2924.

28. R. F. Chen, J. L. Shi, Y. Ma, G. Q. Lin, X. J. Lang and C. Wang, Angew Chem Int Edit, 2019, 58, 6430-6434.

29. P. Das and S. K. Mandal, Chemistry of Materials, 2019, 31, 1584-1596.

30. S. Gu, S. F. Wu, L. J. Cao, M. C. Li, N. Qin, J. Zhu, Z. Q. Wang, Y. Z. Li, Z. Q. Li, J. J. Chen and Z. G. Lu, J Am Chem Soc, 2019, 141, 9623-9628.

31. F. Xu, S. H. Yang, X. Chen, Q. H. Liu, H. J. Li, H. Q. Wang, B. Q. Wei and D. L. Jiang, Chemical science, 2019, 10, 60016006.

32. L. L. Wang, C. Zeng, H. Xu, P. C. Yin, D. C. Chen, J. Deng, M. Li, N. Zheng, C. Gu and Y. G. Ma, Chemical science, 2019, 10, 1023-1028.

33. Z. Meng, R. M. Stolz and K. A. Mirica, J Am Chem Soc, 2019, 141, 11929-11937.

34. P. J. Waller, F. Gandara and O. M. Yaghi, Accounts Chem Res, 2015, 48, 3053-3063.

35. S. B. Jin, X. S. Ding, X. Feng, M. Supur, K. Furukawa, S. Takahashi, M. Addicoat, M. E. El-Khouly, T. Nakamura, S. Irle, S. Fukuzumi, A. Nagai and D. L. Jiang, Angew Chem Int Edit, 2013, 52, 2017-2021.

36. M. Dogru, M. Handloser, F. Auras, T. Kunz, D. Medina, A. Hartschuh, P. Knochel and T. Bein, Angew Chem Int Edit, 2013, 52, 2920-2924.

37. B. Lukose, A. Kuc, J. Frenzel and T. Heine, Beilstein J Nanotech, 2010, 1, 60-70.

38. S. B. Jin, M. Supur, M. Addicoat, K. Furukawa, L. Chen, T. Nakamura, S. Fukuzumi, S. Irle and D. L. Jiang, J Am Chem Soc, 2015, 137, 7817-7827.

39. L. Stegbauer, K. Schwinghammer and B. V. Lotsch, Chemical science, 2014, 5, 2789-2793.

40. K. Schwinghammer, B. Tuffy, M. B. Mesch, E. Wirnhier, C. Martineau, F. Taulelle, W. Schnick, J. Senker and B. V. Lotsch, Angew Chem Int Edit, 2013, 52, 2435-2439.

41. J. S. Zhang, X. F. Chen, K. Takanabe, K. Maeda, K. Domen, J. D. Epping, X. Z. Fu, M. Antonietti and X. C. Wang, Angew Chem Int Edit, 2010, 49, 441-444.

42. R. P. Bisbey and W. R. Dichtel, ACS central science, 2017, 3, 533-543.

43. S. Y. Ding and W. Wang, Chemical Society reviews, 2013, 42, 548-568.

44. Y. F. Zeng, R. Q. Zou and Y. L. Zhao, Advanced materials, 2016, 28, 2855-2873.

45. S. S. Yuan, X. Li, J. Y. Zhu, G. Zhang, P. Van Puyvelde and B. Van der Bruggen, Chemical Society reviews, 2019, 48, 26652681.

46. H. Wang, Z. T. Zeng, P. Xu, L. S. Li, G. M. Zeng, R. Xiao, Z. Y. Tang, D. L. Huang, L. Tang, C. Lai, D. N. Jiang, Y. Liu, H. Yi, L. Qin, S. J. Ye, X. Y. Ren and W. W. Tang, Chemical Society reviews, 2019, 48, 488-516.

47. H. Wang, D. Jiang, D. Huang, G. Zeng, P. Xu, C. Lai, M. Chen, M. Cheng, C. Zhang and Z. Wang, Journal of Materials Chemistry A, 2019, 7, 22848-22870.
48.

H. M. El-Kaderi, J. R. Hunt, J. L. Mendoza-Cortes, A. P. Cote, R. E. Taylor, M. O'Keeffe and O. M. Yaghi, Science, 2007, 316, 268-272.

49. J. F. Dienstmaier, D. D. Medina, M. Dogru, P. Knochel, T. Bein, W. M. Heckl and M. Lackinger, ACS nano, 2012, 6, 7234-7242.

50. S. Wan, J. Guo, J. Kim, H. Ihee and D. L. Jiang, Angew Chem Int Edit, 2009, 48, 5439-5442.

51. C. H. Liu, W. Zhang, Q. D. Zeng and S. B. Lei, Chem-Eur J, 2016, 22, 6768-6773.

52. B. J. Smith and W. R. Dichtel, J Am Chem Soc, 2014, 136, 8783-8789.

53. B. T. Koo, R. F. Heden and P. Clancy, Phys Chem Chem Phys, 2017, 19, 9745-9754.

54. N. L. Campbell, R. Clowes, L. K. Ritchie and A. I. Cooper, Chemistry of Materials, 2009, 21, 204-206.

55. M. Calik, F. Auras, L. M. Salonen, K. Bader, I. Grill, M. Handloser, D. D. Medina, M. Dogru, F. Lobermann, D. Trauner, A. Hartschuh and T. Bein, J Am Chem Soc, 2014, 136, 17802-17807.

56. S. B. Jin, K. Furukawa, M. Addicoat, L. Chen, S. Takahashi, S. Irle, T. Nakamura and D. L. Jiang, Chemical science, 2013, 4, 4505-4511.

57. E. L. Spitler and W. R. Dichtel, Nature chemistry, 2010, 2, 672-677.

58. N. Huang, L. P. Zhai, D. E. Coupry, M. A. Addicoat, K. Okushita, K. Nishimura, T. Heine and D. L. Jiang, Nature communications, 2016, 7, 12325.

59. S. Dalapati, E. Q. Jin, M. Addicoat, T. Heine and D. L. Jiang, J Am Chem Soc, 2016, 138, 5797-5800.

60. C. Jiang, M. Tang, S. L. Zhu, J. D. Zhang, Y. C. Wu, Y. Chen, C. Xia, C. L. Wang and W. P. Hu, Angew Chem Int Edit, 2018, 57, 16072-16076.

61. S. Wang, L. Ma, Q. Y. Wang, P. P. Shao, D. Ma, S. Yuan, P. Lei, P. F. Li, X. Feng and B. Wang, J Mater Chem C, 2018, 6, 5369-5374.

62. V. Nguyen and M. Grunwald, J Am Chem Soc, 2018, 140, 3306-3311.

63. H. Y. Li, A. D. Chavez, H. F. Li, H. Li, W. R. Dichtel and J. L. Bredas, J Am Chem Soc, 2017, 139, 16310-16318.

64. P. Kuhn, M. Antonietti and A. Thomas, Angew Chem Int Edit, 2008, 47, 3450-3453.

65. P. Katekomol, J. Roeser, M. Bojdys, J. Weber and A. Thomas, Chemistry of Materials, 2013, 25, 1542-1548.

66. M. J. Bojdys, J. Jeromenok, A. Thomas and M. Antonietti, Advanced materials, 2010, 22, 2202-2205.

S. Dey, A. Bhunia, D. Esquivel and C. Janiak, Journal of Materials Chemistry A, 2016, 4, 6259-6263.

P. Puthiaraj, S. M. Cho, Y. R. Lee and W. S. Ahn, Journal of Materials Chemistry A, 2015, 3, 6792-6797.

S. Y. Yu, J. Mahmood, H. J. Noh, J. M. Seo, S. M. Jung, S. H. Shin, Y. K. Im, I. Y. Jeon and J. B. Baek, Angew Chem Int Edit, 2018, 57, 8438-8442.

70. K. W. Wang, L. M. Yang, X. Wang, L. P. Guo, G. Cheng, C. Zhang, S. B. Jin, B. Tan and A. Cooper, Angew Chem Int Edit, 2017, 56, 14149-14153.

71. M. Liu, Q. Huang, S. Wang, Z. Li, B. Li, S. Jin and B. Tan, Angewandte Chemie, 2018, 57, 11968-11972.

72. M. Y. Liu, L. P. Guo, S. B. Jin and B. E. Tan, Journal of Materials Chemistry A, 2019, 7, 5153-5172. 
73. X. C. Wang, K. Maeda, A. Thomas, K. Takanabe, G. Xin, J. M Carlsson, K. Domen and M. Antonietti, Nature materials, 2009, 8, 76-80.

74. A. Mishra, A. Mehta, S. Basu, N. P. Shetti, K. R. Reddy and T. M. Aminabhavi, Carbon, 2019, 149, 693-721.

75. X. Jiang, P. Wang and J. J. Zhao, Journal of Materials Chemistry A, 2015, 3, 7750-7758.

76. J. J. Xie, S. A. Shevlin, Q. S. Ruan, S. J. A. Moniz, Y. R. Liu, X. Liu, Y. M. Li, C. C. Lau, Z. X. Guo and J. W. Tang, Energy \& Environmental Science, 2018, 11, 1617-1624.

77. D. J. Martin, K. P. Qiu, S. A. Shevlin, A. D. Handoko, X. W. Chen, Z. X. Guo and J. W. Tang, Angew Chem Int Edit, 2014, 53, 9240-9245.

78. F. J. Uribe-Romo, J. R. Hunt, H. Furukawa, C. Klock, M. O'Keeffe and O. M. Yaghi, J Am Chem Soc, 2009, 131, 45704571

79. Y. X. Ma, Z. J. Li, L. Wei, S. Y. Ding, Y. B. Zhang and W. Wang, J Am Chem Soc, 2017, 139, 4995-4998.

80. G. Q. Lin, H. M. Ding, D. Q. Yuan, B. S. Wang and C. Wang, J Am Chem Soc, 2016, 138, 3302-3305.

81. S. Y. Ding, J. Gao, Q. Wang, Y. Zhang, W. G. Song, C. Y. Su and W. Wang, J Am Chem Soc, 2011, 133, 19816-19822.

82. S. B. Jin, T. Sakurai, T. Kowalczyk, S. Dalapati, F. Xu, H. Wei, X. Chen, J. Gao, S. Seki, S. Irle and D. L. Jiang, Chem-Eur J, 2014, 20, 14608-14613.

83. T. Y. Zhou, S. Q. Xu, Q. Wen, Z. F. Pang and X. Zhao, J Am Chem Soc, 2014, 136, 15885-15888.

84. Z. F. Pang, S. Q. Xu, T. Y. Zhou, R. R. Liang, T. G. Zhan and X. Zhao, J Am Chem Soc, 2016, 138, 4710-4713.

85. X. Chen, M. Addicoat, E. Q. Jin, H. Xu, T. Hayashi, F. Xu, N. Huang, S. Irle and D. L. Jiang, Scientific reports, 2015, 5, 14650.

86. J. Y. Yue, Y. P. Mo, S. Y. Li, W. L. Dong, T. Chen and D. Wang, Chemical science, 2017, 8, 2169-2174.

87. Y. Z. Liu, Y. H. Ma, Y. B. Zhao, X. X. Sun, F. Gandara, H. Furukawa, Z. Liu, H. Y. Zhu, C. H. Zhu, K. Suenaga, P. Oleynikov, A. S. Alshammari, X. Zhang, O. Terasaki and O. M. Yaghi, Science, 2016, 351, 365-369.

88. S. Wan, F. Gandara, A. Asano, H. Furukawa, A. Saeki, S. K. Dey, L. Liao, M. W. Ambrogio, Y. Y. Botros, X. F. Duan, S. Seki, J. F. Stoddart and O. M. Yaghi, Chemistry of Materials, 2011, 23, 4094-4097.

89. S. Kandambeth, A. Mallick, B. Lukose, M. V. Mane, T. Heine and R. Banerjee, J Am Chem Soc, 2012, 134, 19524-19527.

90. S. Chandra, S. Kandambeth, B. P. Biswal, B. Lukose, S. M Kunjir, M. Chaudhary, R. Babarao, T. Heine and R. Banerjee, J Am Chem Soc, 2013, 135, 17853-17861.

91 B. P. Biswal, S. Chandra, S. Kandambeth, B. Lukose, T. Heine and R. Banerjeet, J Am Chem Soc, 2013, 135, 5328-5331.

92. M. Bhadra, S. Kandambeth, M. K. Sahoo, M. Addicoat, E. Balaraman and R. Banerjee, J Am Chem Soc, 2019, 141, 6152-6156.

93.

P. Pachfule, A. Acharjya, J. Roeser, T. Langenhahn, M. Schwarze, R. Schomacker, A. Thomas and J. Schmidt, J Am Chem Soc, 2018, 140, 1423-1427.

94. S. L. Lu, Y. M. Hu, S. Wan, R. McCaffrey, Y. H. Jin, H. W. Gu and W. Zhang, J Am Chem Soc, 2017, 139, 17082-17088.

95. M. R. Rao, Y. Fang, S. De Feyter and D. F. Perepichka, J Am Chem Soc, 2017, 139, 2421-2427.

96. F. J. Uribe-Romo, C. J. Doonan, H. Furukawa, K. Oisaki and O. M. Yaghi, J Am Chem Soc, 2011, 133, 11478-11481.
97. D. N. Bunck and W. R. Dichtel, J Am Chem Soc, 2013, 135, 14952-14955.

98. K. Gottschling, L. Stegbauer, G. Sayasci, N. A. Prisco, Z. J. Berkson, C. Ochsenfeld, B. F. Chmelka and B. V. Lotsch, Chemistry of Materials, 2019, 31, 1946-1955.

99. X. J. Zhao, P. Pachfule, S. Li, T. Langenhahn, M. Y. Ye, C. Schlesiger, S. Praetz, J. Schmidt and A. Thomas, J Am Chem Soc, 2019, 141, 6623-6630.

100. W. T. Liu, Q. Su, P. Y. Ju, B. X. Guo, H. Zhou, G. H. Li and Q. L. Wu, ChemSusChem, 2017, 10, 664-669.

S. Dalapati, S. B. Jin, J. Gao, Y. H. Xu, A. Nagai and D. L. Jiang, J Am Chem Soc, 2013, 135, 17310-17313.

102. Y. L. Zhu, S. Wan, Y. H. Jin and W. Zhang, J Am Chem Soc, 2015, 137, 13772-13775.

103. S. B. Alahakoon, C. M. Thompson, A. X. Nguyen, G. Occhialini, G. T. McCandless and R. A. Smaldone, Chem Commun, 2016, 52, 2843-2845.

104. V. S. Vyas, F. Haase, L. Stegbauer, G. Savasci, F. Podjaski, C. Ochsenfeld and B. V. Lotsch, Nature communications, 2015, 6, 8508.

105. F. Haase, T. Banerjee, G. Savasci, C. Ochsenfeld and B. V. Lotsch, Faraday Discuss, 2017, 201, 247-264.

106. Q. R. Fang, Z. B. Zhuang, S. Gu, R. B. Kaspar, J. Zheng, J. H. Wang, S. L. Qiu and Y. S. Yan, Nature communications, 2014, 5, 4503.

107.

A. P. Cote, H. M. El-Kaderi, H. Furukawa, J. R. Hunt and O. M. Yaghi, J Am Chem Soc, 2007, 129, 12914-12915.

108. Q. R. Fang, J. H. Wang, S. Gu, R. B. Kaspar, Z. B. Zhuang, J. Zheng, H. X. Guo, S. L. Qiu and Y. S. Yan, J Am Chem Soc, 2015, 137, 8352-8355.

109. Z. Luo, L. Liu, J. Ning, K. Lei, Y. Lu, F. Li and J. Chen, Angewandte Chemie, 2018, 57, 9443-9446.

C. L. Zhang, S. M. Zhang, Y. H. Yan, F. Xia, A. N. Huang and Y. Z. Xian, ACS applied materials \& interfaces, 2017, 9, 13415-13421.

111. S. J. Lyle, T. M. O. Popp, P. J. Waller, X. K. Pei, J. A. Reimer and O. M. Yaghi, J Am Chem Soc, 2019, 141, 11253-11258.

112. J. R. Hunt, C. J. Doonan, J. D. LeVangie, A. P. Cote and O. M. Yaghi, J Am Chem Soc, 2008, 130, 11872-11873.

113. J. Guo, Y. H. Xu, S. B. Jin, L. Chen, T. Kaji, Y. Honsho, M. A. Addicoat, J. Kim, A. Saeki, H. Ihee, S. Seki, S. Irle, M. Hiramoto, J. Gao and D. L. Jiang, Nature communications, 2013, 4, 2736.

114. A. Nagai, X. Chen, X. Feng, X. S. Ding, Z. Q. Guo and D. L. Jiang, Angew Chem Int Edit, 2013, 52, 3770-3774.

115. K. T. Jackson, T. E. Reich and H. M. El-Kaderi, Chem Commun, 2012, 48, 8823-8825.

116. D. A. Pyles, J. W. Crowe, L. A. Baldwin and P. L. McGrier, Acs Macro Lett, 2016, 5, 1055-1058.

117. Y. H. Cho, C. Y. Lee, D. C. Ha and C. H. Cheon, Adv Synth Catal, 2012, 354, 2992-2996.

118. B. Nath, W. H. Li, J. H. Huang, G. E. Wang, Z. H. Fu, M. S. Yao and G. Xu, Crystengcomm, 2016, 18, 4259-4263.

119. Y. Du, H. S. Yang, J. M. Whiteley, S. Wan, Y. H. Jin, S. H. Lee and W. Zhang, Angew Chem Int Edit, 2016, 55, 1737-1741. X. D. Zhuang, W. X. Zhao, F. Zhang, Y. Cao, F. Liu, S. Bia and X. L. Feng, Polymer Chemistry, 2016, 7, 4176-4181.

121. X. L. Li, C. L. Zhang, S. L. Cai, X. H. Lei, V. Altoe, F. Hong, J. J. Urban, J. Ciston, E. M. Chan and Y. Liu, Nature communications, 2018, 9, 2998.

122. H. Z. Lv, X. L. Zhao, H. Y. Niu, S. J. He, Z. Tang, F. C. Wu and J. P. Giesy, J Hazard Mater, 2019, 369, 494-502. 
123. H. Y. Liu, J. Chu, Z. L. Yin, X. Cai, L. Zhuang and H. X. Deng, Chem-Us, 2018, 4, 1696-1709.

124. G. Das, B. P. Biswal, S. Kandambeth, V. Venkatesh, G. Kaur, M. Addicoat, T. Heine, S. Verma and R. Banerjee, Chemical science, 2015, 6, 3931-3939.

125. P. Pachfule, S. Kandmabeth, A. Mallick and R. Banerjee, Chem Commun, 2015, 51, 11717-11720.

126. S. J. He, T. Zeng, S. H. Wang, H. Y. Niu and Y. Q. Cai, ACS applied materials \& interfaces, 2017, 9, 2959-2965.

127. B. J. Smith, L. R. Parent, A. C. Overholts, P. A. Beaucage, R. P. Bisbey, A. D. Chavez, N. Hwang, C. Park, A. M. Evans, N. C. Gianneschi and W. R. Dichtel, ACS central science, 2017, 3, 58-65.

128. C. B. Ong, L. Y. Ng and A. W. Mohammad, Renew Sust Energ Rev, 2018, 81, 536-551.

129. D. Beydoun, R. Amal, G. Low and S. McEvoy, Journal of Nanoparticle Research, 1999, 1, 439-458.

130. X. F. Duan and C. M. Lieber, Advanced materials, 2000, 12, 298-302.

131. B. Luo, G. Liu and L. Z. Wang, Nanoscale, 2016, 8, 69046920.

132. J. Di, J. Xiong, H. M. Li and Z. Liu, Advanced materials, 2018, 30, 1704548.

133. K. Nakata and A. Fujishima, J Photoch Photobio C, 2012, 13, 169-189.

134. S. Ida and T. Ishihara, Journal of Physical Chemistry Letters, 2014, 5, 2533-2542.

135. K. X. Yao, Y. L. Chen, Y. Lu, Y. F. Zhao and Y. Ding, Carbon, 2017, 122, 258-265.

136. I. Berlanga, M. L. Ruiz-Gonzalez, J. M. Gonzalez-Calbet, J. L. G. Fierro, R. Mas-Balleste and F. Zamora, Small, 2011, 7, 1207-1211.

137. I. Berlanga, R. Mas-Balleste and F. Zamora, Chem Commun, 2012, 48, 7976-7978.

138. J. W. Colson, A. R. Woll, A. Mukherjee, M. P. Levendorf, E. L. Spitler, V. B. Shields, M. G. Spencer, J. Park and W. R. Dichtel, Science, 2011, 332, 228-231.

139. Z. Zha, L. Xu, Z. Wang, X. Li, Q. Pan, P. Hu and S. Lei, ACS applied materials \& interfaces, 2015, 7, 17837-17843.

140. J. I. Feldblyum, C. H. McCreery, S. C. Andrews, T. Kurosawa, E. J. G. Santos, V. Duong, L. Fang, A. L. Ayzner and Z. N. Bao, Chem Commun, 2015, 51, 13894-13897.

141. K. Dey, M. Pal, K. C. Rout, H. S. Kunjattu, A. Das, R. Mukherjee, U. K. Kharul and R. Banerjee, J Am Chem Soc, 2017, 139, 13083-13091.

142. Y. Chen, H. J. Cui, J. Q. Zhang, K. Zhao, D. F. Ding, J. Guo, L. S. Li, Z. Y. Tian and Z. Y. Tang, Rsc Adv, 2015, 5, 9257392576.

143. Y. C. Yuan, B. Sun, A. M. Cao, D. Wang and L. J. Wan, Chem Commun, 2018, 54, 5976-5979.

144. H. Yang, X. P. Cheng, X. X. Cheng, F. S. Pan, H. Wu, G. H. Liu, Y. M. Song, X. Z. Cao and Z. Y. Jiang, Journal of Membrane Science, 2018, 565, 331-341.

145. X. Zhang, Z. Wang, L. Yao, Y. Y. Mai, J. Q. Liu, X. L. Hua and H. Wei, Materials Letters, 2018, 213, 143-147.

146. W. Huang, Z. J. Wang, B. C. Ma, S. Ghasimi, D. Gehrig, F. Laquai, K. Landfester and K. A. I. Zhang, Journal of Materials Chemistry A, 2016, 4, 7555-7559.

147. B. Gole, V. Stepanenko, S. Rager, M. Grune, D. D. Medina, T. Bein, F. Wurthner and F. Beuerle, Angew Chem Int Edit, 2018, 57, 846-850.

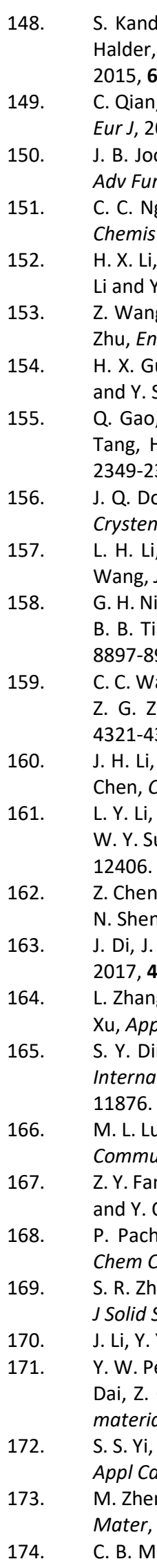

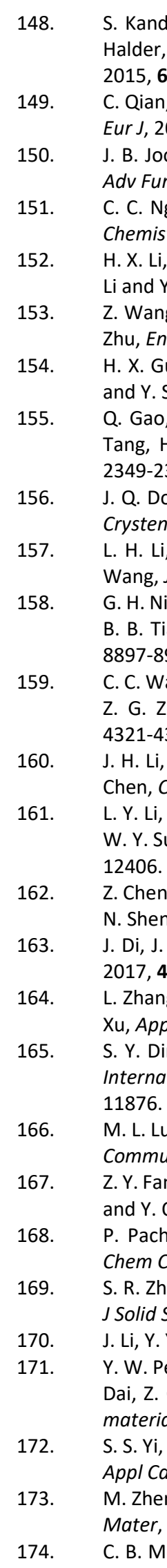

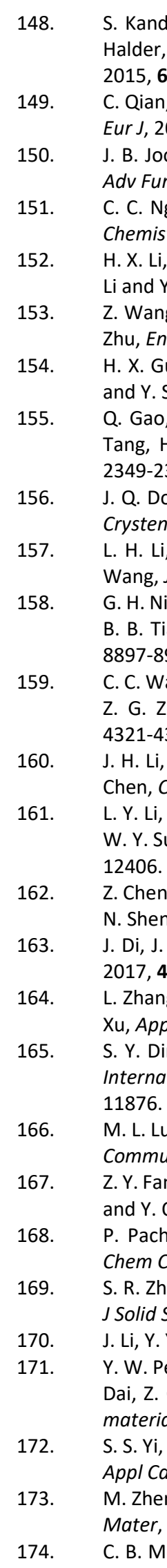

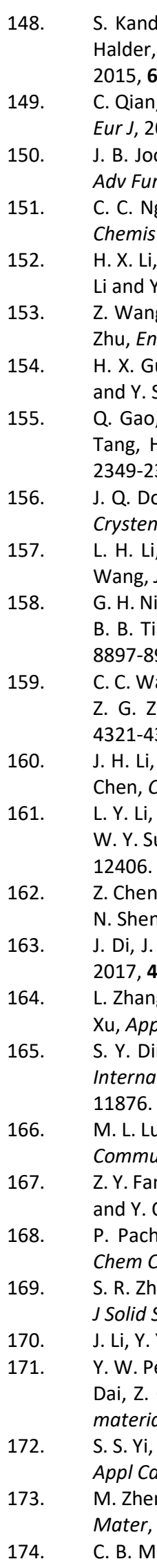

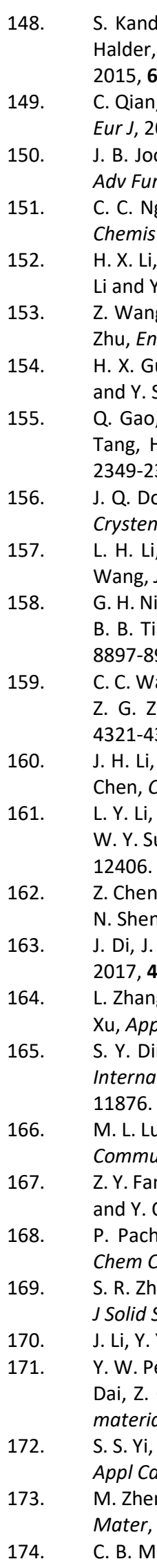

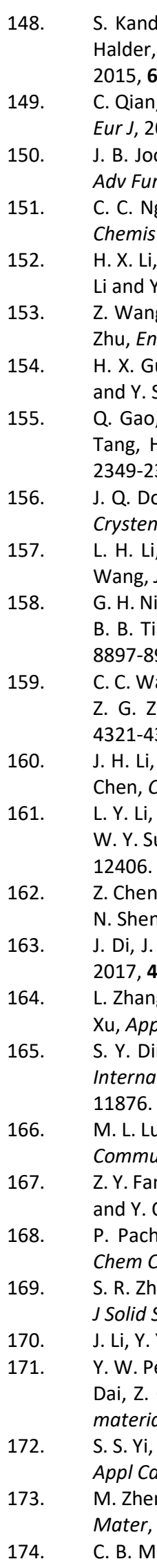

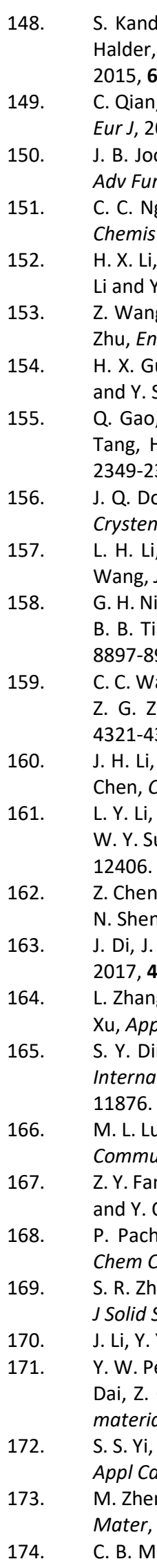

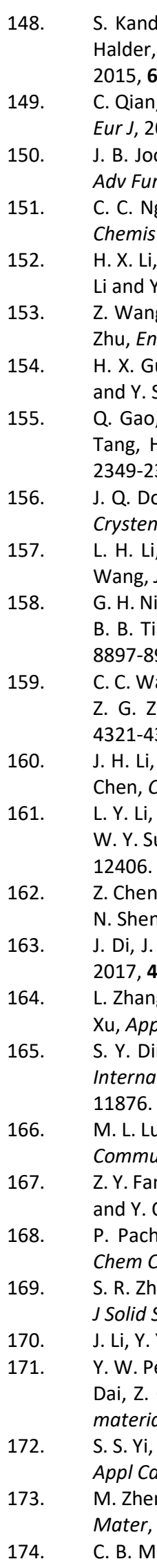

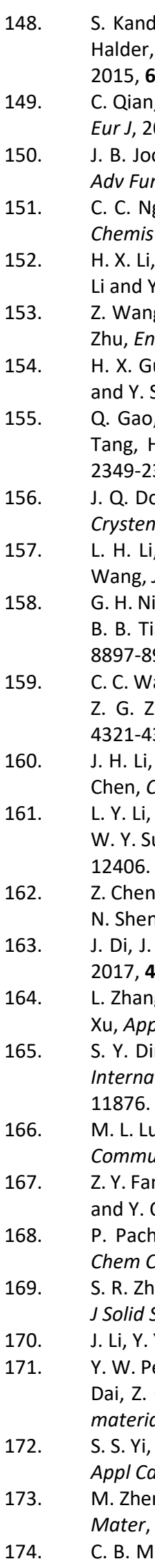

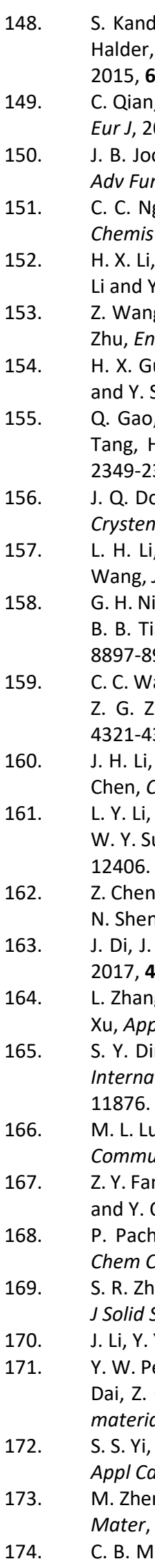

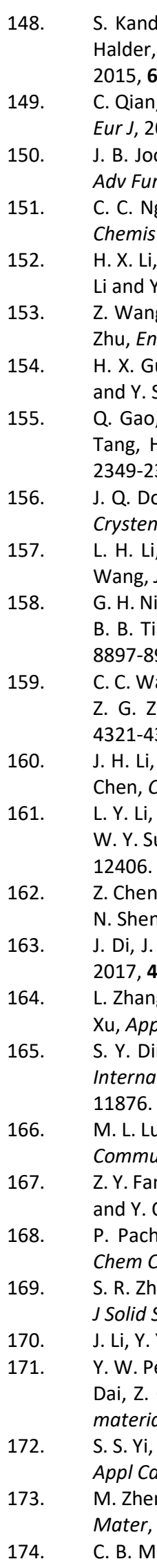

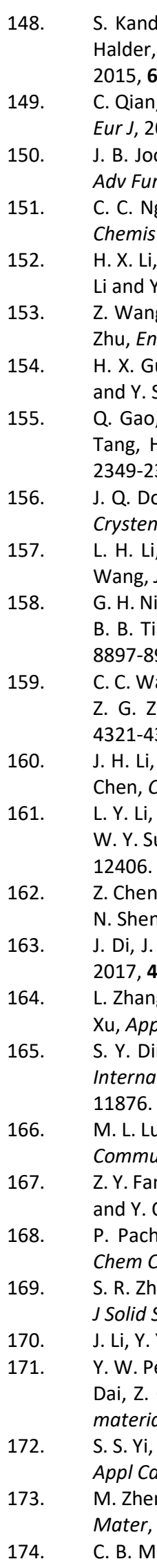

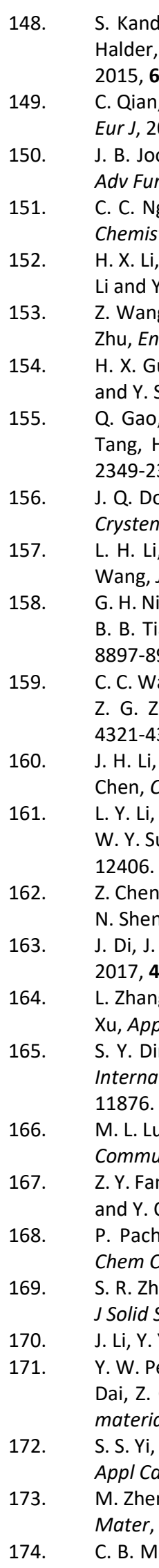

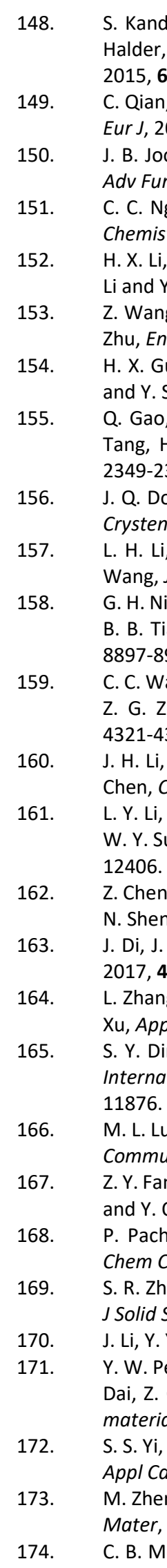

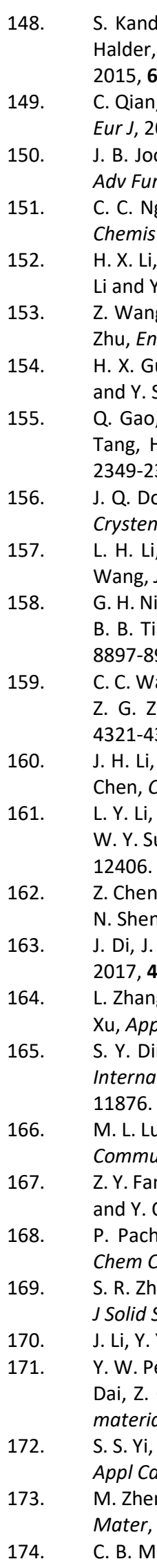

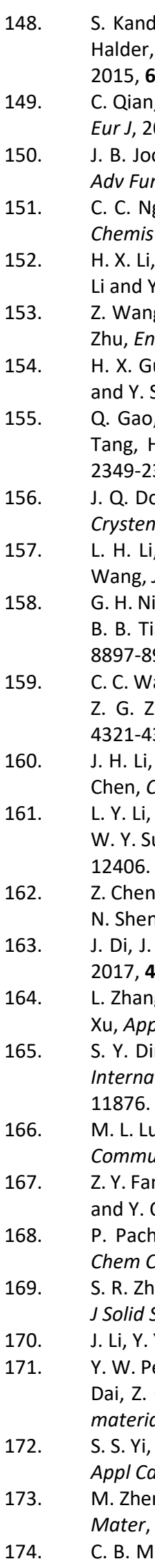

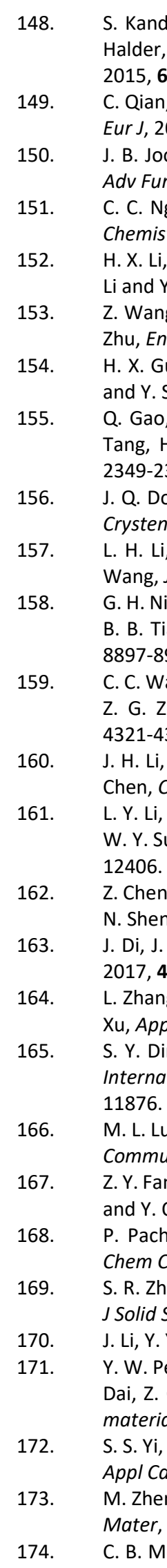

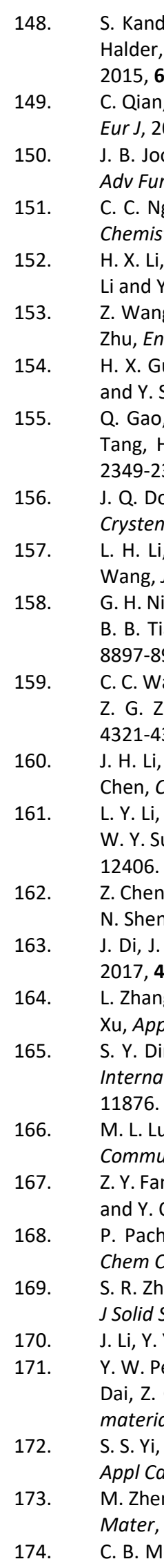

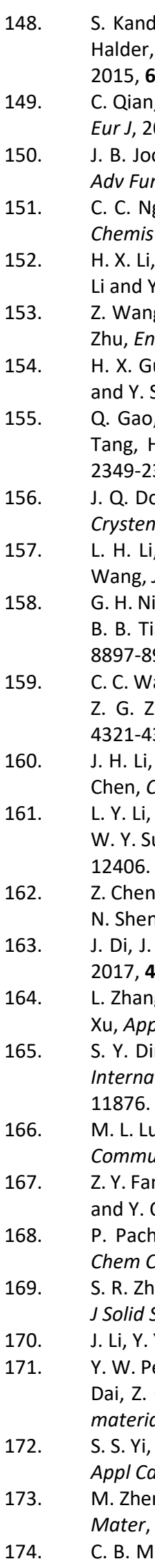

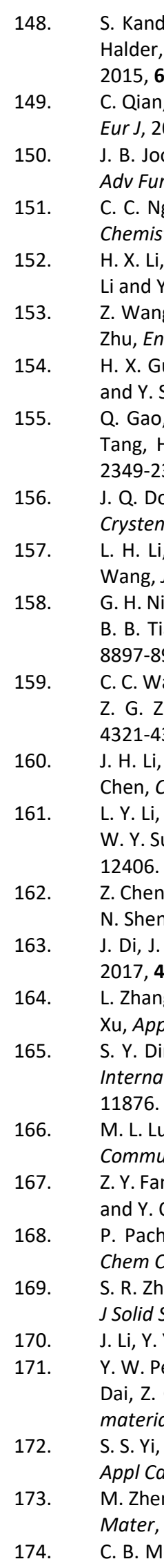

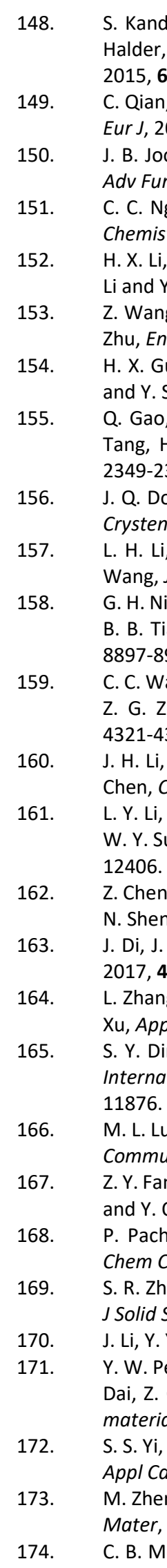

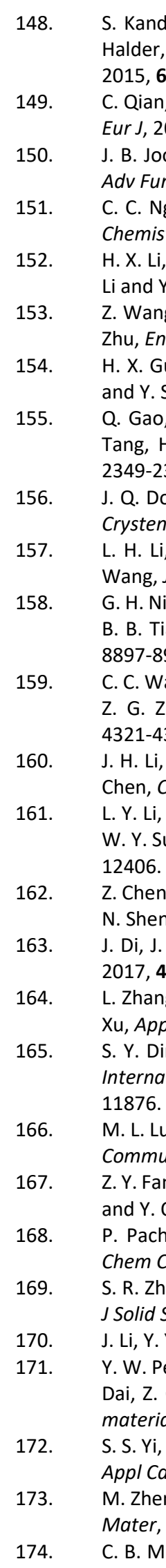

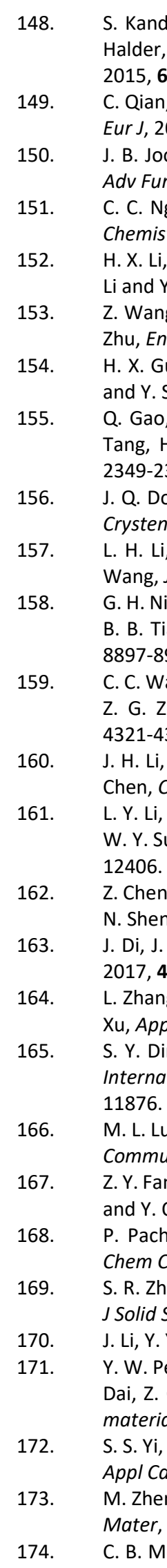

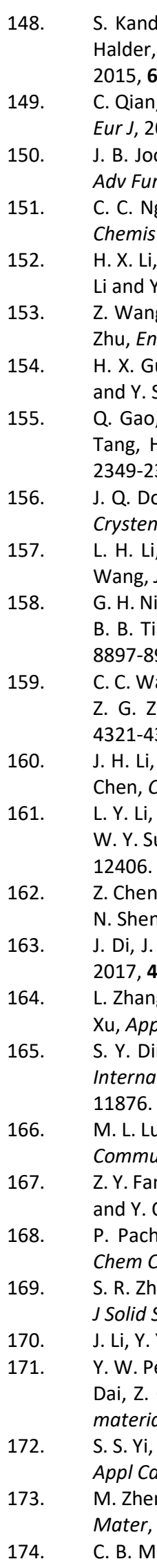

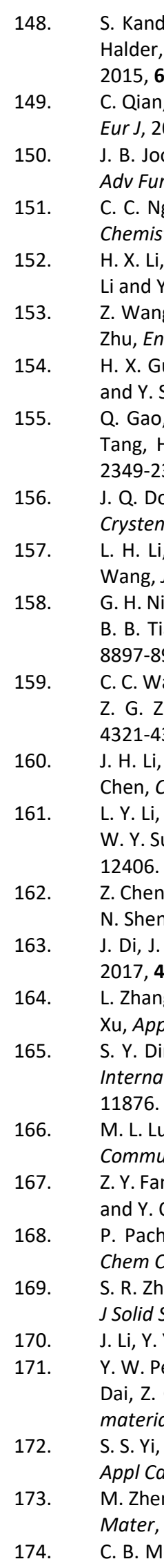

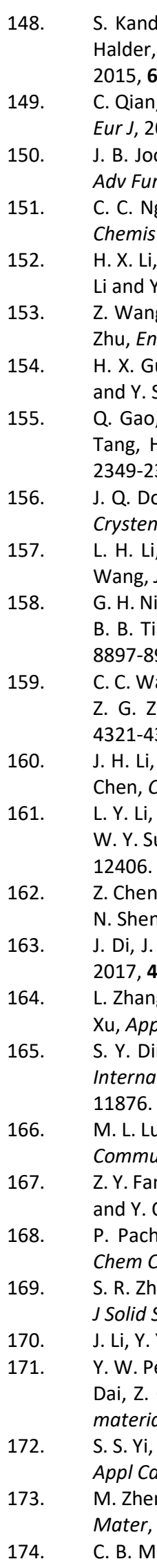

C. B. Meier, R. S. Sprick, A. Monti, P. Guiglion, J. S. M. Lee, M. A. Zwijnenburg and A. I. Cooper, Polymer, 2017, 126, 283-290. 
175. L. P. Guo, Y. L. Niu, S. Razzaque, B. Tan and S. B. Jin, Acs Catal, 2019, 9, 9438-9445.

176. T. Ishi-i, K. Yaguma, T. Thiemann, M. Yashima, K. Ueno and S. Mataka, Chem Lett, 2004, 33, 1244-1245.

177. L. Stegbauer, S. Zech, G. Savasci, T. Banerjee, F. Podjaski, K. Schwinghammer, C. Ochsenfeld and B. V. Lotsch, Adv Energy Mater, 2018, 8, 1703278.

178. R. S. Sprick, B. Bonillo, R. Clowes, P. Guiglion, N. J. Brownbill, B. J. Slater, F. Blanc, M. A. Zwijnenburg, D. J. Adams and A. I. Cooper, Angew Chem Int Edit, 2016, 55, 1824-1828.

179. X. Y. Wang, L. J. Chen, S. Y. Chong, M. A. Little, Y. Z. Wu, W. H. Zhu, R. Clowes, Y. Yan, M. A. Zwijnenburg, R. S. Sprick and A. I. Cooper, Nature chemistry, 2018, 10, 1180-1189.

180. J. L. Sheng, H. Dong, X. B. Meng, H. L. Tang, Y. H. Yao, D. Q. Liu, L. L. Bai, F. M. Zhang, J. Z. Wei and X. J. Sun, Chemcatchem, 2019, 11, 2313-2319.

181. W. Huang, Q. He, Y. P. Hu and Y. G. Li, Angew Chem Int Edit, 2019, 58, 8676-8680.

182. F. Li, D. K. Wang, Q. J. Xing, G. Zhou, S. S. Liu, Y. Li, L. L. Zheng, P. Ye and J. P. Zou, Appl Catal B-Environ, 2019, 243, 621-628.

183. J. H. Yang, D. G. Wang, H. X. Han and C. Li, Accounts Chem Res, 2013, 46, 1900-1909.

184. W. T. Eckenhoff, W. R. McNamara, P. W. Du and R. Eisenberg, Bba-Bioenergetics, 2013, 1827, 958-973.

185. P. W. Du and R. Eisenberg, Energy \& Environmental Science, 2012, 5, 6012-6021.

186. J. He, L. Chen, F. Wang, Y. Liu, P. Chen, C. T. Au and S. F. Yin, ChemSusChem, 2016, 9, 624-630.

187. X. Q. Hao, Z. L. Jin, H. Yang, G. X. Lu and Y. P. Bi, Appl Catal B-Environ, 2017, 210, 45-56.

188. Q. Q. Jiang, L. Sun, J. H. Bi, S. J. Liang, L. Y. Li, Y. Yu and L. $\mathrm{Wu}$, ChemSusChem, 2018, 11, 1108-1113.

189. J. L. Dempsey, B. S. Brunschwig, J. R. Winkler and H. B. Gray, Accounts Chem Res, 2009, 42, 1995-2004.

190. T. Banerjee, F. Haase, G. Savasci, K. Gottschling, C. Ochsenfeld and B. V. Lotsch, J Am Chem Soc, 2017, 139, 16228-16234.

191. B. P. Biswal, H. A. Vignolo-Gonzalez, T. Banerjee, L. Grunenberg, G. Savasci, K. Gottschling, J. Nuss, C. Ochsenfeld and B. V. Lotsch, J Am Chem Soc, 2019, 141, 11082-11092.

192. J. W. Tang, J. R. Durrant and D. R. Klug, J Am Chem Soc, 2008, 130, 13885-13891.

193. S. Bi, C. Yang, W. B. Zhang, J. S. Xu, L. M. Liu, D. Q. Wu, X. C. Wang, Y. Han, Q. F. Liang and F. Zhang, Nature communications, 2019, 10, 2467.

194. E. Q. Jin, Z. A. Lan, Q. H. Jiang, K. Y. Geng, G. S. Li, X. C. Wang and D. L. Jiang, Chem-Us, 2019, 5, 1632-1647.

195. D. Kong, X. Y. Han, J. J. Xie, Q. S. Ruan, C. D. Windle, S. Gadipelli, K. Shen, Z. M. Bai, Z. X. Guo and J. W. Tang, Acs Catal, 2019, 9, 7697-7707.

196. A. Dhakshinamoorthy, S. Navalon, A. Corma and H. Garcia, Energy \& Environmental Science, 2012, 5, 9217-9233.

197. W. L. Yu, D. F. Xu and T. Y. Peng, Journal of Materials Chemistry A, 2015, 3, 19936-19947.

198. T. M. Di, B. C. Zhu, B. Cheng, J. G. Yu and J. S. Xu, J Catal, 2017, 352, 532-541.

199. R. Xu, X. S. Wang, H. Zhao, H. Lin, Y. B. Huang and R. Cao, Catal Sci Technol, 2018, 8, 2224-2230.
200.

201.

B. Wang, J Photoch Photobio C, 2019, 38, 1-26.

H. Yi, M. Yan, D. L. Huang, G. M. Zeng, C. Lai, M. F. Li, X. Q. Huo, L. Qin, S. Y. Liu, X. G. Liu, B. S. Li, H. Wang, M. C. Shen, Y. K. Fu and X. Y. Guo, Appl Catal B-Environ, 2019, 250, 5262.

202. R. Jaiswal, N. Patel, A. Dashora, R. Fernandes, M. Yadav, R. Edla, R. S. Varma, D. C. Kothari, B. L. Ahuja and A. Miotello, Appl Catal B-Environ, 2016, 183, 242-253.

203. H. Safajou, H. Khojasteh, M. Salavati-Niasari and S. Mortazavi-Derazkola, J Colloid Interf Sci, 2017, 498, 423432.

204. J. X. Low, J. G. Yu, M. Jaroniec, S. Wageh and A. A. AlGhamdi, Advanced materials, 2017, 29, 1601694.

205. C. Y. Wang, Y. J. Zhang, W. K. Wang, D. N. Pei, G. X. Huang, J. J. Chen, X. Zhang and H. Q. Yu, Appl Catal B-Environ, 2018, 221, 320-328.

206. Y. Mi, L. Y. Wen, Z. J. Wang, D. W. Cao, R. Xu, Y. G. Fang, Y. L. Zhou and Y. Lei, Nano Energy, 2016, 30, 109-117.

207. F. L. Wang, P. Chen, Y. P. Feng, Z. J. Xie, Y. Liu, Y. H. Su, Q. X. Zhang, Y. F. Wang, K. Yao, W. Y. Lv and G. G. Liu, Appl Catal B-Environ, 2017, 207, 103-113.

208.

N. Xu, R. L. Wang, D. P. Li, X. Meng, J. L. Mu, Z. Y. Zhou and Z. M. Su, Dalton T, 2018, 47, 4191-4197.

209. F. Niu, L. M. Tao, Y. C. Deng, H. Gao, J. G. Liu and W. G. Song, New J Chem, 2014, 38, 5695-5699.

210. S. J. He, Q. F. Rong, H. Y. Niu and Y. Q. Cai, Chem Commun, 2017, 53, 9636-9639.

Q. H. Liang, Z. Li, Z. H. Huang, F. Y. Kang and Q. H. Yang, Adv Funct Mater, 2015, 25, 6885-6892.

212. J. Q. Pan, L. P. Guo, S. Q. Zhang, N. Wang, S. B. Jin and B. Tan, Chem-Asian J, 2018, 13, 1674-1677.

W. N. Wang, W. J. An, B. Ramalingam, S. Mukherjee, D. M. Niedzwiedzki, S. Gangopadhyay and P. Biswas, J Am Chem Soc, 2012, 134, 11276-11281.

214. C. T. Dinh, H. Yen, F. Kleitz and T. O. Do, Angew Chem Int Edit, 2014, 53, 6618-6623.

215. Y. M. Zhang, Y. M. Hu, J. H. Zhao, E. Park, Y. H. Jin, Q. J. Liu and W. Zhang, Journal of Materials Chemistry A, 2019, 7, 16364-16371.

216. S. R. Zhu, Q. Qi, Y. Fang, W. N. Zhao, M. K. Wu and L. Han, Cryst Growth Des, 2018, 18, 883-891.

217. S. J. He, Q. F. Rong, H. Y. Niu and Y. Q. Cai, Appl Catal BEnviron, 2019, 247, 49-56.

218. X. W. Wu, X. Han, Q. S. Xu, Y. H. Liu, C. Yuan, S. Yang, Y. Liu, J. W. Jiang and Y. Cui, J Am Chem Soc, 2019, 141, 70817089.

219. A. K. Beine, A. J. D. Kruger, J. Artz, C. Weidenthaler, C. Glotzbach, P. J. C. Hausoul and R. Palkovits, Green Chem, 2018, 20, 1316-1322.

220. Y. J. Li, S. H. Zheng, X. Liu, P. Li, L. Sun, R. X. Yang, S. Wang, Z. S. Wu, X. H. Bao and W. Q. Deng, Angew Chem Int Edit, 2018, 57, 7992-7996.

221. H. Wei, S. Z. Chai, N. T. Hu, Z. Yang, L. M. Wei and L. Wang, Chem Commun, 2015, 51, 12178-12181.

222. S. J. Ren, M. J. Bojdys, R. Dawson, A. Laybourn, Y. Z. Khimyak, D. J. Adams and A. I. Cooper, Advanced materials, 2012, 24, 2357-2361.

223. G. Lin, C. H. Gao, Q. Zheng, Z. X. Lei, H. J. Geng, Z. Lin, H. H. Yang and Z. W. Cai, Chem Commun, 2017, 53, 3649-3652. 
224. Y. W. Peng, W. K. Wong, Z. G. Hu, Y. D. Cheng, D. Q. Yuan, S. A. Khan and D. Zhao, Chemistry of Materials, 2016, 28, 5095-5101.

225. Y. C. Deng, L. Tang, C. Y. Feng, G. M. Zeng, J. J. Wang, Y. Y. Zhou, Y. N. Liu, B. Peng and H. P. Feng, J Hazard Mater, 2018, 344, 758-769.

226. J. Tang, L. Tang, H. P. Feng, G. M. Zeng, H. R. Dong, C. Zhang, B. B. Huang, Y. C. Deng, J. J. Wang and Y. Y. Zhou, J Hazard Mater, 2016, 320, 581-590. 